\title{
Medição e modelagem simplificada da vegetação para simulação digital da iluminação natural
}

\author{
Measurement and modeling of simplified trees for \\ daylighting computer simulation
}

\section{Eliana de Fátima Costa Lima Solange Maria Leder}

\begin{abstract}
Resumo
$\mathbf{P}$

rever o efeito da vegetação arbórea no desempenho da iluminação natural é uma tarefa complexa e difícil, pois depende da reprodução precisa da passagem da luz através de suas copas. Variáveis como tamanho da folha, sua forma, refletância e transparência, entre outras, devem ser consideradas. Assim, modelar uma árvore reproduzindo exatamente a situação real é impraticável, não só devido à quantidade e complexidade das variáveis, como também por causa da sobrecarga do modelo. Nesse quadro, esta pesquisa tem por objetivos: aprimorar um método de medição da permeabilidade da vegetação arbórea à passagem da luz natural, que chamamos de "fração de lacuna da copa", utilizando a fotografia hemisférica e a análise de imagens; e aplicar as medidas resultantes em modelos digitais tridimensionais simplificados, para utilização em simulação computacional da luz natural. Três modelos experimentais, denominados de "persianas", "translúcido" e "frestas", foram desenvolvidos para simular quatro espécies arbóreas. Os níveis de iluminação em situação real e simulada de cada um foram comparados e validados segundo os indicadores MBE e RMSE relativos. O modelo "frestas", por exemplo, mostrou-se adequado às espécies pitombeira e carolina, com MBE relativo de 0,21 e $-0,12 \mathrm{e}$ RMSE relativo de 0,02 e 0,03 respectivamente, o que comprova a pertinência do método desenvolvido.
\end{abstract}

Palavras-chave: Iluminação natural. Copas arbóreas. Simulação computacional.
Eliana de Fátima Costa Lima Instituto Federal da Paraíba Itaporanga - PB - Brasil

Solange Maria Leder Universidade Federal da Paraíba João Pessoa - PB - Brasil

Recebido em 28/11/2015

Aceito em 22/10/16

\begin{abstract}
Predicting the effect of arboreal vegetation on daylight performance is a complex and difficult task as it depends on accurately simulating the passage of light through its canopy. Variables such as leaf size, shape, reflectance and transparency, among others, should be considered. Thus, modeling a tree exactly simulating the real situation is impractical, not only because of the quantity and complexity of the variables, but also because of the overload of the model. In this context, the main aims of this research are: to improve the way of measuring the permeability of arboreal vegetation to daylight, which we call the "canopy gap fraction", using hemispherical photography and image analysis; and apply these measurements in simplified three-dimensional digital models to use in computational daylight simulations. Three digital models, namely "blinds", "translucent", and "gaps" were developed, simulating four tree species. The actual and simulated light levels of each one were compared and validated according to the relative MBE and RMSE indicators. The "gap" tree model, for example, was especially suitable for the Pitombeira and Carolina tree species, with relative $M B E$ values of 0.21 and -0.12 , as well as relative RMSE values of 0.02 and 0.03 , respectively, proving the relevance of the developed method.
\end{abstract}

Keywords: Daylight. Tree canopy. Computer simulation.

LIMA, E. de F. C.; LEDER, S. M. Medição e modelagem simplificada da vegetação para simulação digital da iluminação 233 natural. Ambiente Construído, Porto Alegre, v. 17, n. 4, p. 233-252, out./dez. 2017. ISSN 1678-8621 Associação Nacional de Tecnologia do Ambiente Construído. 


\section{Introdução}

Os fatores que influenciam a disponibilidade da luz natural são diversos, entre os quais podemos destacar a obstrução do entorno. Elementos naturais como a vegetação arbórea podem provocar obstrução considerável, alterando a quantidade de luz natural no interior dos ambientes (HOPKINSON;

LONGMORE; PETHERBRIDGE, 1975). Além dos benefícios decorrentes da economia de energia e da melhoria das condições ambientais, a vegetação arbórea pode melhorar a qualidade da luz que incide sobre as aberturas, reduzindo a intensidade da componente direta do sol, bem como o brilho vindo do céu. A vegetação pode filtrar e suavizar a luz através das folhas, ramos e troncos (ALSALLAL; AL-RAIS, 2013).

Variáveis como a forma da copa das árvores e seu tamanho determinam a área sombreada, que muda de acordo com a espécie, a idade e a época do ano. A definição da espécie vegetativa adequada deve levar em consideração as mudanças de forma e dimensão, que se processarão ao longo do tempo, sendo importante basear-se nas condições de insolação do local e na necessidade de sombreamento em cada situação (MASCARÓ; MOORE, 2010).

A vegetação é um elemento de difícil inserção no projeto da iluminação natural. Considerando, por exemplo, a simulação computacional, em que todos os elementos intervenientes na reprodução da luz devem ser modelados tridimensionalmente, para simular um ambiente com árvores é necessário que os modelos tridimensionais representem adequadamente a vegetação em análise. Variáveis como altura e geometria da copa, quantidade, dimensão e espaçamento das folhas, dimensão do tronco, dos ramos e dos galhos, os índices de refletância, opacidade e transparência dos materiais, entre outras, devem ser inseridas no modelo tridimensional. Contudo, essa modelagem é impraticável, não somente devido à complexidade da medição de todas as variáveis envolvidas no processo, como também por causa da sobrecarga do modelo. É necessário simplificar a representação da vegetação, porém sem prejuízo da precisão.

Para Yu e Hien (2006) e Piveta (2010), o impacto da vegetação nas condições ambientais internas de edificações relaciona-se diretamente com o índice de área foliar (IAF) da vegetação. O IAF, área total projetada de folha por unidade de superfície do solo, é um dos mais importantes parâmetros de caracterização da estrutura da copa e processos da vegetação. Para medir o IAF em copas de árvores, a fotografia hemisférica é um método frequentemente utilizado, que apresenta vantagens como baixo tempo de processamento, facilidade de operação e estabelecimento de um registro permanente de informações da copa, como posição, tamanho, densidade e distribuição de abertura (ZHAO et al., 2014). As fotos hemisféricas, empregadas no estudo das copas das árvores, podem ser obtidas por meio de uma câmera fotográfica com uma lente olho de peixe posicionada sob a copa (orientada para o zênite). Lentes olho de peixe possuem distância focal curta e amplo campo de visão, em torno de $180^{\circ}$. Em essência, as fotografias hemisféricas produzem uma projeção de um hemisfério em um plano, e a natureza exata da projeção varia de acordo com a lente utilizada (SCHNEIDER; SCHWALBE; MAAS, 2009). O processamento desse tipo de imagem envolve a classificação dos pixels em céu visível (pixel branco) e céu obstruído (pixel preto), o que gera um mapa do céu. No caso da copa de árvores, a fotografia hemisférica será interpretada como um mapa das "frações de lacuna" e das "frações obstruídas" da visão do céu, considerando o ponto em que a imagem é registrada.

As fotografias olho de peixe capturam os padrões de obstrução e penetração da luz no dossel; assim, a arquitetura da copa e a área de folhagem podem ser quantificadas. As capacidades de discriminação espacial, de aquisição da distribuição angular da folhagem e de quantificação de fração de céu visível através da copa em diferentes ângulos zenitais e azimutais são algumas vantagens dessa técnica (ZHANG; CHEN; MILLER, 2005). A análise de imagens olho de peixe, através de softwares específicos, proporciona um método alternativo para medir a "fração de lacuna" ou a permeabilidade da copa da árvore à passagem da luz. Assim, alguns métodos de caracterização da vegetação têm sido introduzidos para simplificar sua reprodução e modelagem, tendo como critério na construção dos modelos simplificados a "fração de lacuna” (AL-SALLAL; AL-RAIS, 2013).

$\mathrm{O}$ efeito do sombreamento arbóreo sobre $\mathrm{O}$ desempenho térmico de edificações tem sido explorado em pesquisas diversas, tais como a de Bartholomei (2003), Berry, Livesley e Aye (2013), Durante e Nogueira (2013) e Piveta (2010). No entanto, simular e quantificar o efeito das árvores sobre o comportamento da luz natural em ambientes internos é uma área de pesquisa ainda pouco explorada. Assim, a partir de estudos anteriores sobre o tema (AL-SALLAL; AL-RAIS, 2013; VILLALBA; PATTINI; CORREA, 2014), esta pesquisa tem por objetivos: 
(a) aprimorar um método de medição da permeabilidade da vegetação arbórea à passagem da luz natural, que chamamos de "fração de lacuna da copa", utilizando a fotografia hemisférica e a análise de imagens; e

(b) aplicar as medidas resultantes em modelos digitais tridimensionais simplificados, para utilização em simulação computacional da luz natural.

\section{Metodologia}

O método adotado nesta pesquisa compreende dois estágios: investigativo e experimental. O estágio investigativo, realizado in loco, constou de seleção e caracterização das espécies arbóreas, medição de referência da iluminância e aquisição das imagens olho de peixe para posterior identificação das "frações de lacuna" e das "frações obstruídas" da visão do céu das espécies analisadas. O estágio experimental consistiu no processamento das imagens olho de peixe, na construção dos modelos virtuais, nas simulações computacionais e no tratamento e análise estatística dos dados.

\section{Seleção e caracterização das espécies arbóreas}

Os tipos arbóreos utilizados nesta pesquisa foram selecionados entre as espécies existentes no Campus I da Universidade Federal da Paraíba (UFPB), em João Pessoa. A escolha dessa área deveu-se à proximidade e à existência de grande diversidade de espécies arbóreas. Os indivíduos estudados encontram-se na área do Centro de
Tecnologia, conforme indicação na Figura 1. Na seleção das espécies arbóreas consideraram-se os seguintes aspectos: espécies recorrentes no local; portes diferenciados (pequeno, médio e grande); sem podas; folhas com tamanhos e composições diferenciadas; e entorno desobstruído (máximo afastamento de elementos naturais e edificados, objetivando reduzir a componente refletida e o efeito do entorno no desenvolvimento da planta). Assim, foram escolhidos quatro indivíduos, um de cada espécie estudada: mangueira (Mangifera indica), pau-brasil (Caesalpinia echinata), pitombeira (Talisia esculenta) e carolina (Adenanthera pavonina). Os indivíduos 1, 2 e 3, conforme especificados na Figura 1, estão localizados em espaços existentes entre os blocos de salas de aula D, F, G e H, que são edificações de pavimento térreo. $\mathrm{O}$ indivíduo 4 está localizado no estacionamento, próximo ao bloco CTJ, que possui três pavimentos (Figura 1).

O levantamento da dimensão projetada (diâmetro e forma) das copas dos indivíduos em estudo foi realizado in loco, com o auxílio de trena comum. As dimensões verticais foram encontradas mediante fotografias de perfil dos indivíduos em estudo. Essas imagens foram importadas para o AutoCad, e, tendo uma medida real como referência, as dimensões verticais da copa, como também a altura total da árvore, foram estimadas (Quadro 1). Paralelamente ao levantamento geométrico, tendo como base comparativa a cartela de cores da Cibse (CHARTERED..., 2001), foram obtidos os coeficientes de reflexão das superfícies do entorno e das folhas das árvores estudadas.

Figura 1 - Localização e espécies dos indivíduos estudados
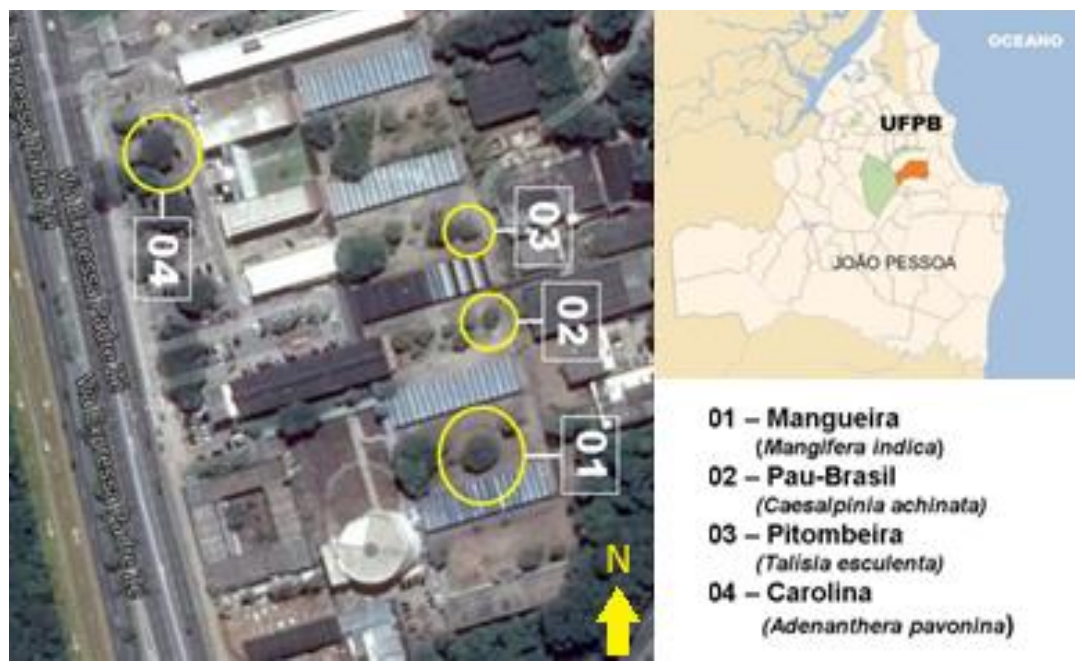

Fonte: adaptada de Google (2014). 
Quadro 1 - Características geométricas das espécies arbóreas selecionadas

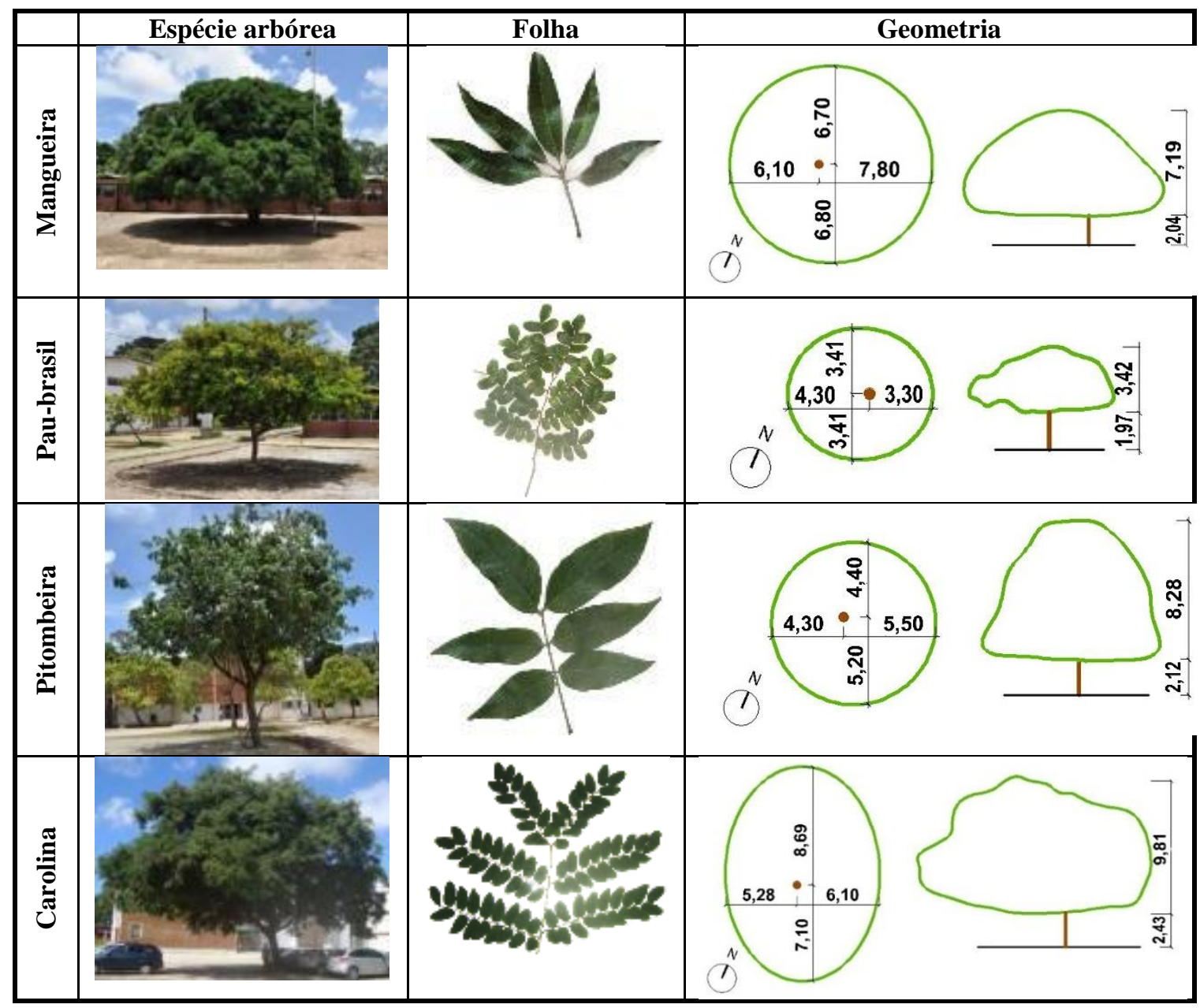

\section{Medição da iluminância}

Nesta etapa foram realizadas medições de iluminância sob a copa de cada indivíduo em estudo. Esses dados serviram de base para posterior validação dos modelos de vegetação utilizados nas simulações computacionais.

As medições ocorreram no período de 10 de junho de 2013 a 30 de julho de 2013, período correspondente ao solstício de inverno, quando as árvores apresentam desenvolvimento foliar significativo. $\mathrm{O}$ horário das medições das iluminâncias ocorreu das $11 \mathrm{~h}$ às $13 \mathrm{~h}$, em intervalos de $1 \mathrm{~min}$, resultando em 120 registros. Esse horário foi estabelecido considerando a maior altitude solar do dia, assim as medições ocorreram em horários em que a projeção da sombra da árvore é menor.

Neste trabalho consideraram-se três categorias de céu para caracterização das condições de iluminação natural: céu claro, céu parcialmente encoberto e céu encoberto. Em cada árvore foram realizadas medições nessas três condições de céu. Em paralelo, através de observações e fotografias, registrou-se o comportamento das nuvens no céu (observou-se o percentual, a distribuição e a aparência das nuvens). Os dados de medição conjugados com essas informações forneceram indicativos para o estabelecimento do tipo de céu. Oito pontos de medição foram locados em torno do tronco de cada árvore, orientados para norte, nordeste, leste, sudeste, sul, sudoeste, oeste e noroeste. Os pontos foram posicionados a 1,5 m a partir do tronco e a uma altura de $1,5 \mathrm{~m}$ a partir do solo (Figura 2).

Para os registros sob as copas foi utilizado um conjunto de oito sensores fotométricos Li-210 LICOR, apoiados em tripés. Os dados foram armazenados em três dataloggers Li 1400 LICOR. Os sensores foram fixados e nivelados com nível de bolha (Figura 3). Simultaneamente aos registros das iluminâncias sob as copas das árvores, foram obtidos também os dados de iluminância externa, utilizados na seleção, 
mediante comparação, dos dias do arquivo climático (Typical Reference Year - TRY) correspondentes aos tipos de céu adotados nesta pesquisa, que, por sua vez, correspondem às datas utilizadas na simulação computacional. Para os registros de iluminância externa foi instalado na cobertura do edifício mais elevado do local um sensor fotométrico Li-210 LI-COR, apoiado em um tripé e conectado a um datalogger Li 1400 LICOR.

\section{Aquisição e processamento das imagens olho de peixe}

Os dados de "fração de lacuna" do dossel, isto é, da porcentagem de céu visto em um ponto abaixo da copa da árvore, foram obtidos a partir das imagens olho de peixe. O procedimento consistiu na captura de imagens sob a copa (para a obtenção dos padrões de obstrução e penetração da luz) e na quantificação da "fração de lacuna" em diferentes ângulos zenitais e azimutais. Para a aquisição das imagens foram usados os seguintes equipamentos: câmera fotográfica Nikon D90; lente Sigma Fisheye circular de $4,5 \mathrm{~mm}$ F/2.8 EX DC HSM com $180^{\circ}$ de abertura e projeção hemisférica; tripé articulado com altura ajustada a $1,5 \mathrm{~m}$ do solo; bússola; e nível de bolha (Figura 4).

Figura 2 - Esquema da locação dos sensores sob a copa da árvore

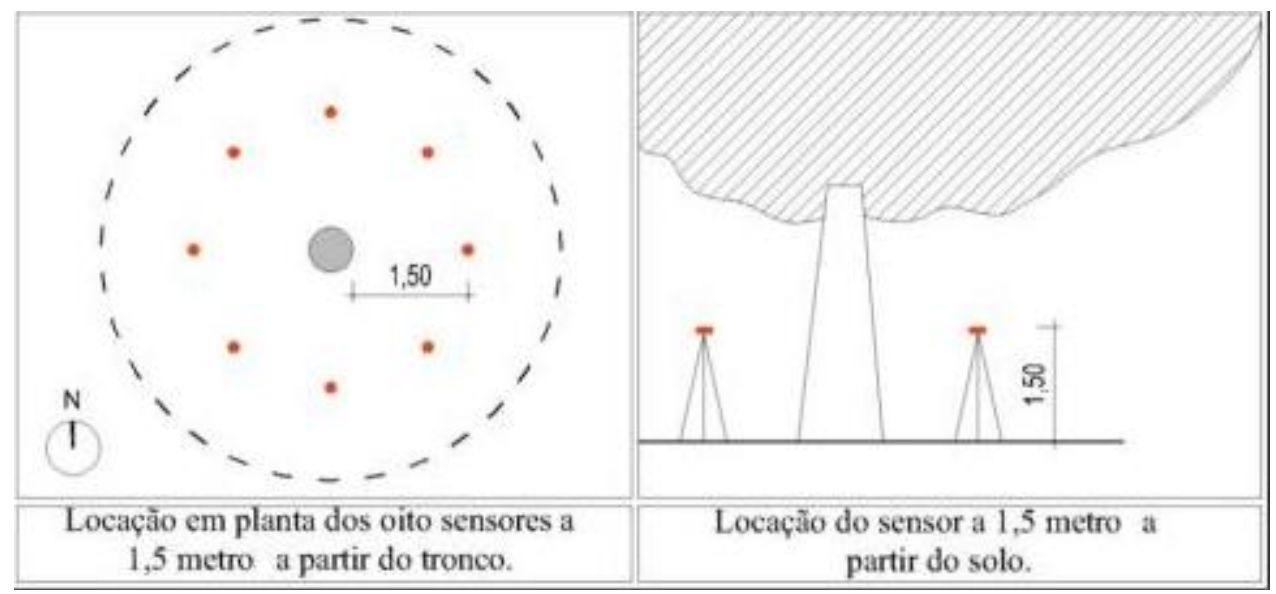

Fonte: Lima (2014).

Figura 3 - (a) Sensor apoiado no tripé e (b) Disposição dos sensores sob a copa da árvore

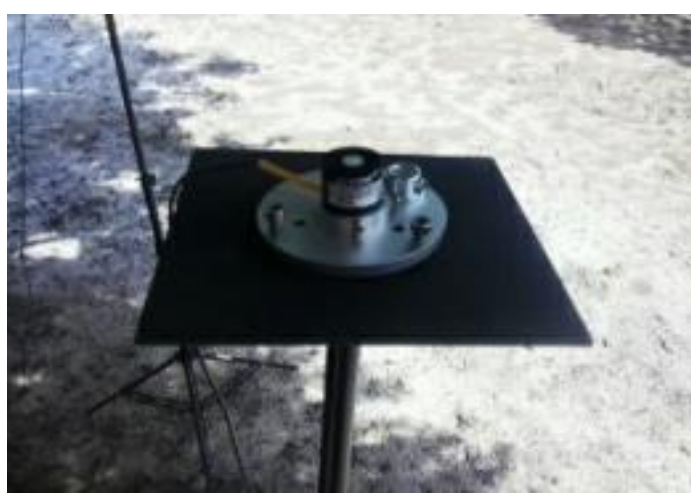

a)

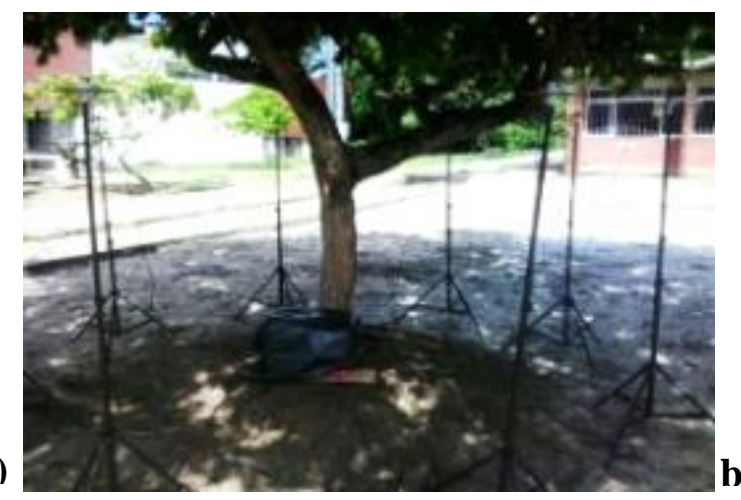

Fonte: Lima (2014). 
Figura 4 - Posicionamento da câmera sob a copa para aquisição das fotografias olho de peixe

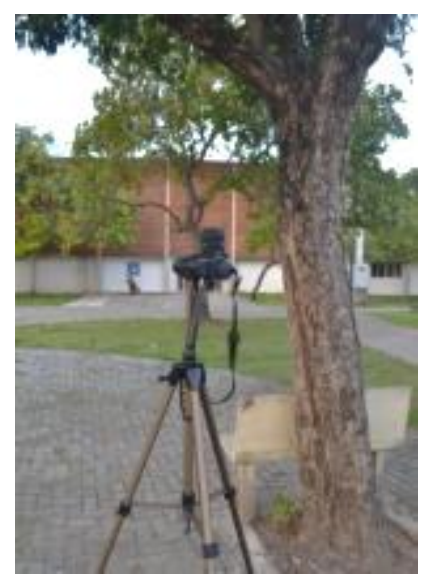

Fonte: Lima (2014).

As imagens foram feitas nos horários do final da tarde, entre $16 \mathrm{~h}$ e $17 \mathrm{~h}$, para que a altura solar não interferisse na fotografia (evitando-se a incidência direta dos raios solares sobre a lente). Esse horário mostrou-se adequado também em relação ao contraste entre as folhas da copa e o céu. Para cada árvore foi obtido um conjunto de oito imagens, com a câmera voltada para o zênite, posicionada a $1,5 \mathrm{~m}$ a partir do tronco da árvore e a $1,5 \mathrm{~m}$ de altura a partir do solo, obedecendo às orientações dos registros da medição da iluminância (norte, nordeste, leste, sudeste, sul, sudoeste, oeste e noroeste) (Quadro 2). Com isso, no processamento das imagens, foi possível substituir os dados nulos de fração de lacuna referentes à presença do tronco.

Para a extração da "fração de lacuna" a partir das fotografias olho de peixe utilizou-se a ferramenta computacional Gap Light Analizer - GLA 2.0, desenvolvida por Frazer, Ganham e Lertzman (1999). Esse aplicativo foi projetado para importar, visualizar e analisar fotografias olho de peixe de copas de árvores. O GLA fornece dados de estrutura do dossel em percentual de abertura, de onde é possível obter a fração de lacuna.

A fotografia olho de peixe foi analisada classificando-se a luz (pixels brancos) e a massa vegetal (pixels negros). Para que isso ocorra, o brilho de cada pixel da foto é calculado em função de uma média de três canais de cores (RGB, vermelho, verde e azul) e transformado em uma escala de cinza. $\mathrm{O}$ threshold é o limiar dessa escala de cinza, e qualquer pixel com valor de brilho acima desse limiar será transformado em pixel branco, e, da mesma forma, valores menores serão transformados em pixel preto.

A extração dos dados de "fração de lacuna" pode ser feita por dois métodos: o primeiro (método I) traça os dados por segmento de céu em intervalos de $10^{\circ}$ em função do ângulo zenital, conforme a Figura 5; o segundo (método II) extrai "frações de lacuna" com base em intervalos iguais de cosseno do ângulo zenital - este produz regiões de céu que possuem iguais pesos de área de céu (Figuras 5 e 6). Nesta pesquisa utilizaram-se ambos os métodos. Para cada região de céu tem-se um valor de "fração de lacuna", portanto para cada fotografia obteve-se um conjunto de 144 dados. Nos dois métodos os dados de fração de lacuna são expressos em valores fracionários, de modo que podem ser expressos em porcentagem. Posteriormente, para cada tipo arbóreo, os resultados do método I (para cada uma das oito fotografias, correspondente às distintas orientações) foram agrupados em planilha, tendo sido calculada a média aritmética dos ângulos zenitais. Assim, obteve-se um dado de fração de lacuna para cada ângulo zenital estabelecido, convertido em porcentagem.

Os resultados do método II foram agrupados em planilha da mesma forma que no método I. No entanto, neste método foi gerado um dado de fração de lacuna para cada combinação de ângulo zenital e azimutal, conduzindo a ocorrências de valores nulos (fração de lacuna $=0$ ), devido à parte da fotografia que corresponde ao tronco da árvore. Assim, foi necessário fazer a substituição das áreas do tronco por áreas de copa. Para isso (Figura 7), em cada fotografia, correspondente a cada orientação, selecionaram-se os dados da porção correspondente a $1 / 8$ da área total, equivalente a $45^{\circ}$ azimutal. Com a reunião dos dados selecionados de cada fotografia, obteve-se a varredura completa da copa sem a presença do tronco da árvore. Os valores fracionários de lacuna foram convertidos em porcentagem, a fim de inseri-los na etapa seguinte, a construção do modelo virtual. 
Quadro 2 - Fotografias olho de peixe sob a pitombeira, com variações na orientação

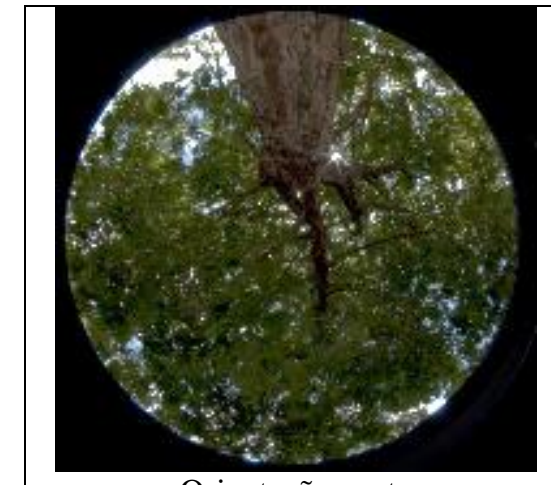

Orientação norte

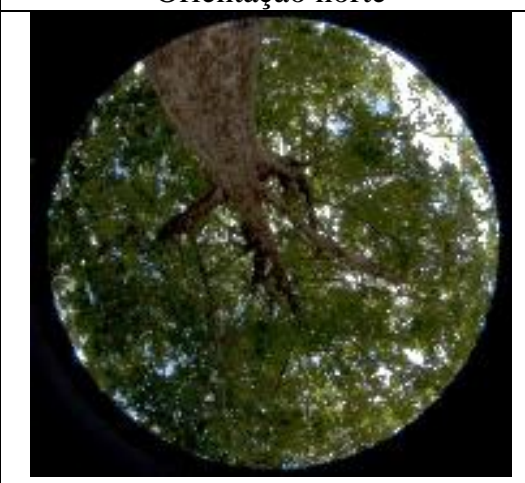

Orientação leste

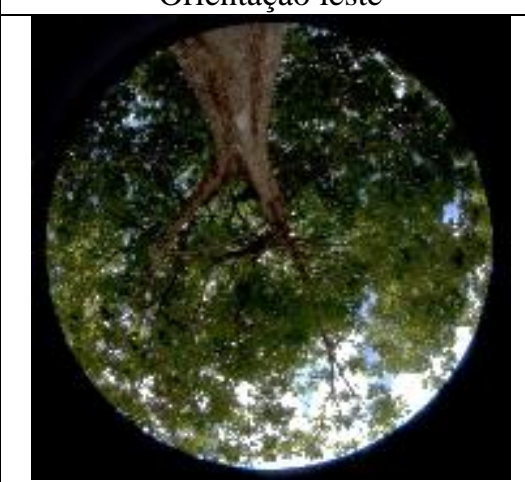

Orientação sul

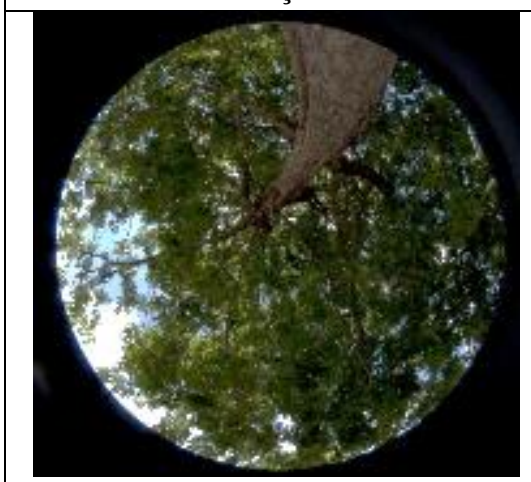

Orientação oeste

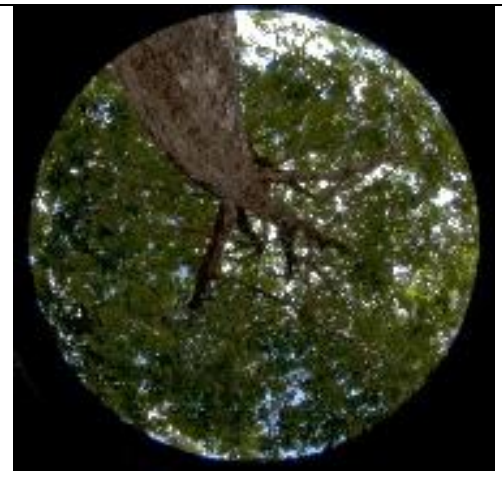

Orientação nordeste

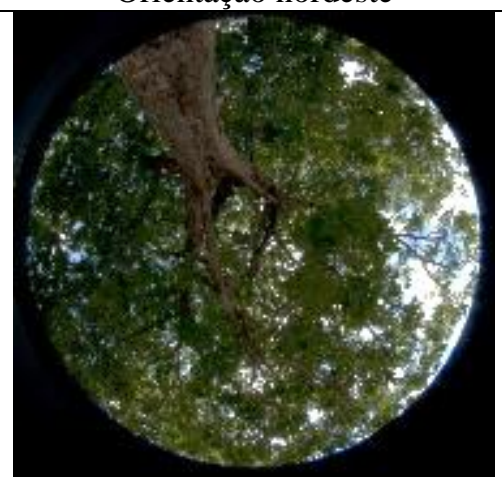

Orientação sudeste

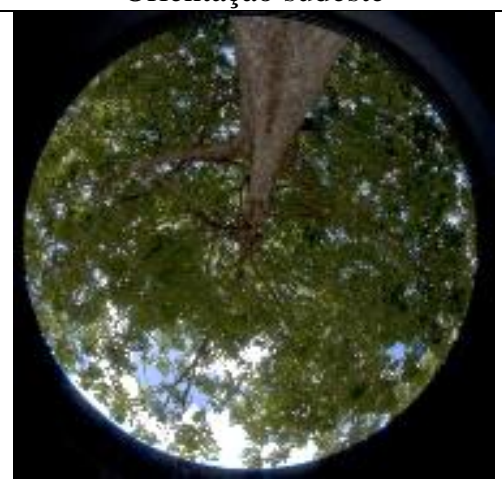

Orientação sudoeste

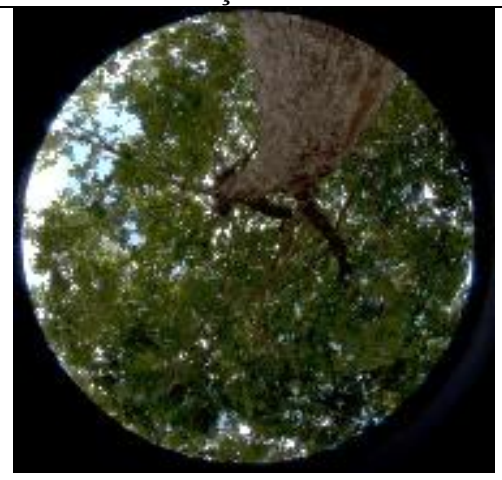

Orientação noroeste

Fonte: Lima (2014). 
Figura 5 - Representação esquemática da divisão angular do mapa de céu - método I

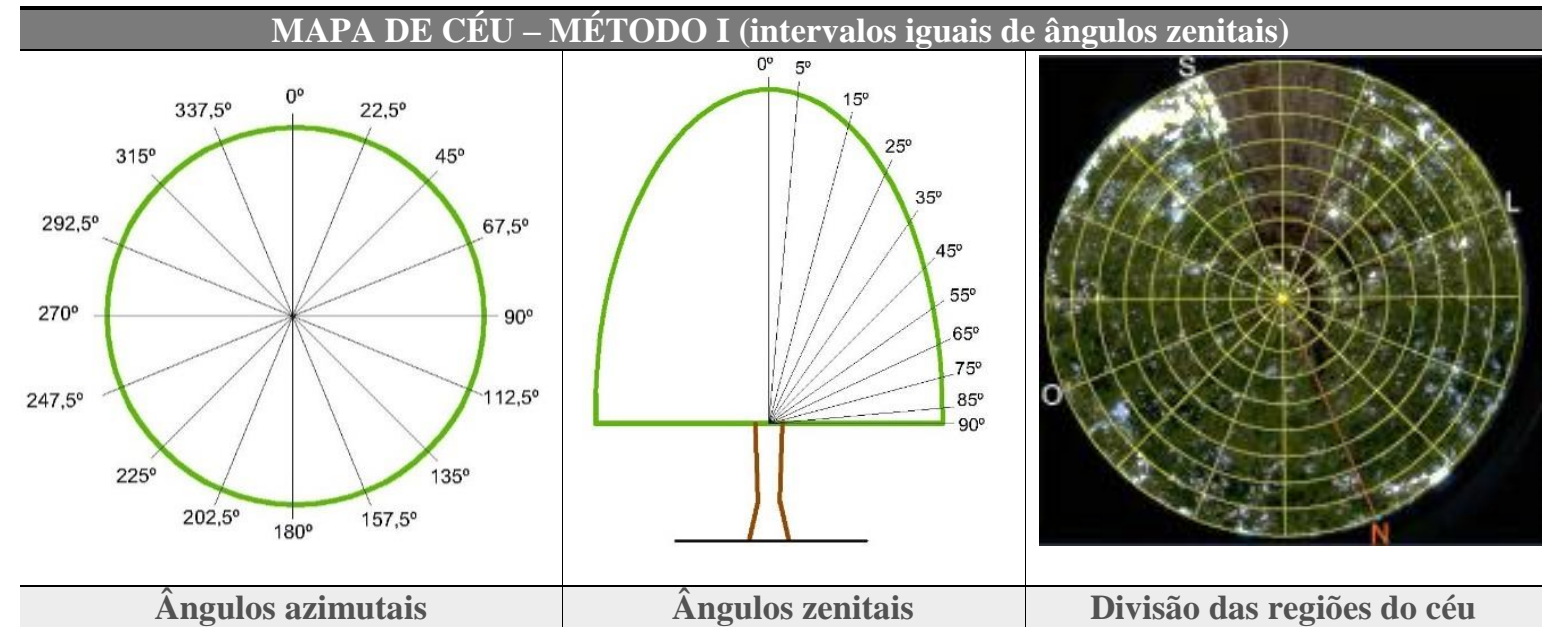

Figura 6 - Representação esquemática da divisão angular do mapa de céu - método II

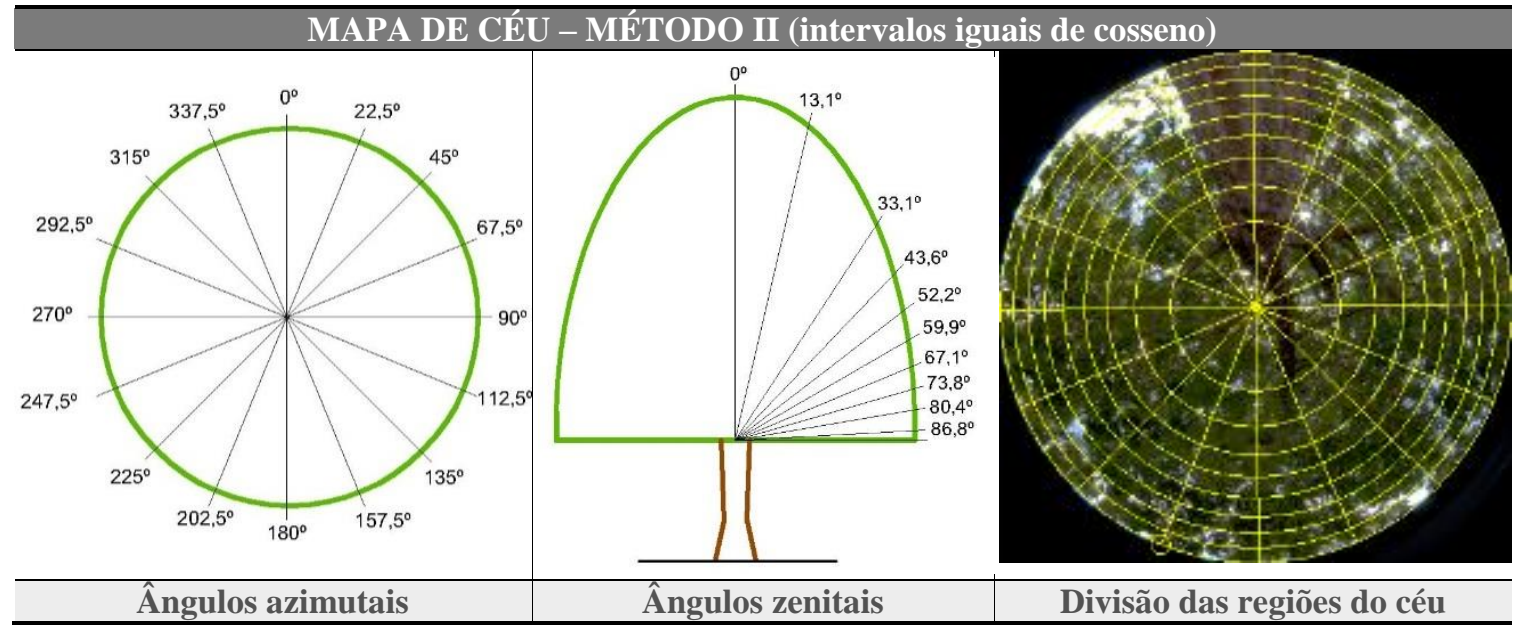

Fonte: Lima (2014).

Figura 7 - Seleção das regiões para varredura da copa (eliminação do tronco)

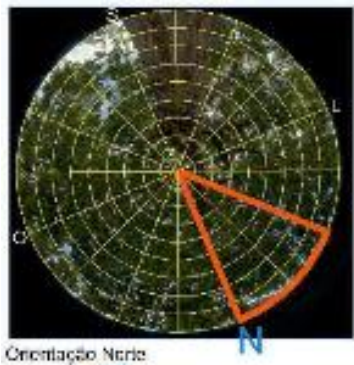

Crectiaçoso Nerve

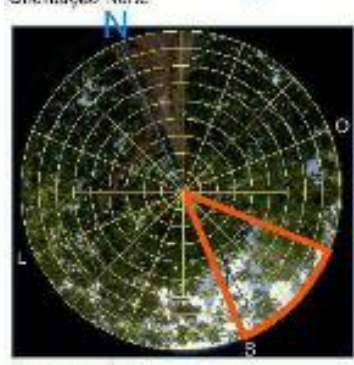

Crisintaç̧o Sul

Fonte: Lima (2014)

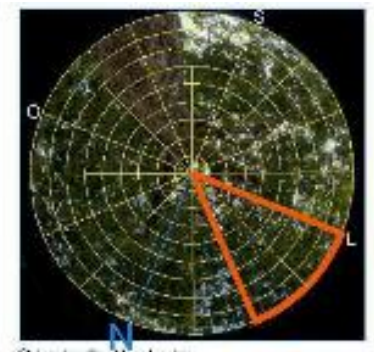

Cricriaçân Yerdente

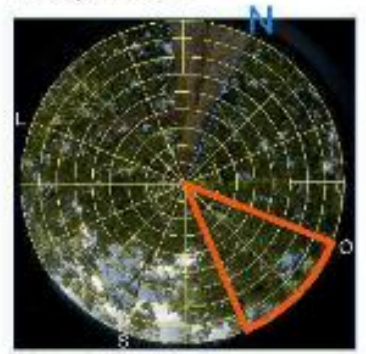

Ofien sacis Sudoes.8

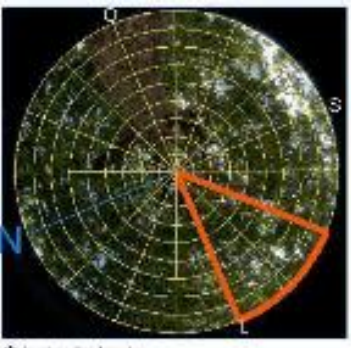

Orierbyat Lesis

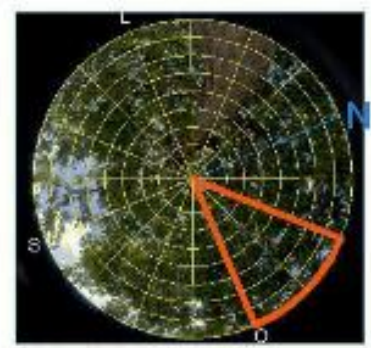

encritacto Dess

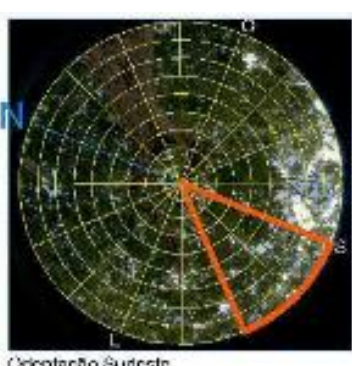

Crontnçกิ Esurisstr

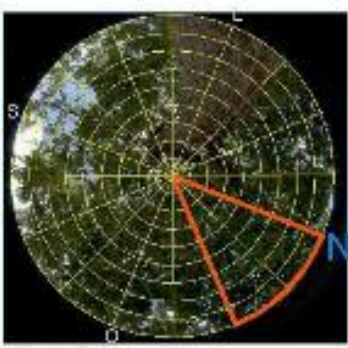

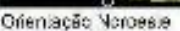




\section{Construção dos modelos virtuais e simulações computacionais}

O modelo simplificado da copa de cada tipo arbóreo estudado assumiu a forma de um semielipsoide, levando em consideração os dados da geometria das árvores levantadas na fase de pesquisa de campo. Para a construção dos modelos foi utilizada a ferramenta computacional SketchUp 8, na foi possível exportar o modelo em formato 3D. A forma-base (o modelo) representa a superfície mais externa da copa arbórea, dividida em 144 regiões, com 9 segmentos na direção zenital e 16 na direção azimutal, conforme mostrado nas Figuras 5 e 6, na seção anterior. A partir dessa forma foram criados três modelos simplificados de representação da copa.

O primeiro modelo é baseado em All-Salal e AlRais (2013). Os autores empregaram uma série de superfícies inclinadas (persianas) dispostas horizontalmente em torno do centro da copa. O tamanho da seção transversal de cada persiana é fixo, mas a inclinação é variável, correlacionandose com os dados de "fração de lacuna" do método I, adquiridos na fase de processamento das imagens. Aplicou-se um valor de gap para cada segmento da copa em intervalos de $10^{\circ}$, em função do ângulo zenital. As persianas foram distribuídas uniformemente ao longo do perfil da árvore, com quatro persianas em cada um dos segmentos zenitais. Cada persiana corresponde a $25 \%$ da abertura de cada segmento (Figura 8).
No segundo modelo de representação da copa empregou-se material translúcido na superfície da copa, associando-se os dados de fração de lacuna do método I, descrito na fase de processamento das imagens à transmitância do material (Figura 9). Em cada segmento do ângulo azimutal foi empregado um material translúcido diferenciado, para que na fase posterior (simulação) fossem inseridos os dados de fração de lacuna.

$\mathrm{Na}$ construção do terceiro modelo foram utilizados os dados de fração de lacuna, extraídos a partir do segundo método descrito na etapa de processamento das imagens olho de peixe. O método adotado para a construção desse modelo foi o de frestas. Em cada região do modelo (combinação de ângulo zenital e azimutal) inseriuse uma abertura correspondente ao percentual de lacuna, verificado com os dados de "fração de lacuna" (Figura 10).

Além do modelo da copa de cada tipo arbóreo, foram modelados os troncos, respeitando-se as dimensões verificadas in loco. O conjunto árvoretronco foi inserido no entorno modelado conforme a disposição e geometria das edificações (Figura 11), bem como as refletâncias das superfícies (pisos e paredes) verificadas com a cartela de cores da Cibse (CHARTERED..., 2001). Os modelos gerados foram importados para o software de simulação da luz natural.

Figura 8 - Modelo geométrico - método das persianas

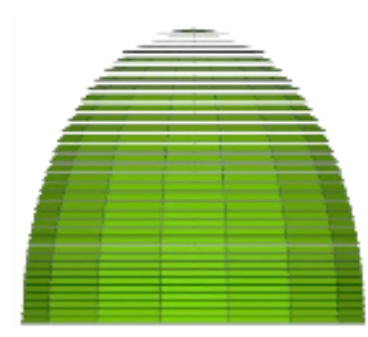

Vista frontal

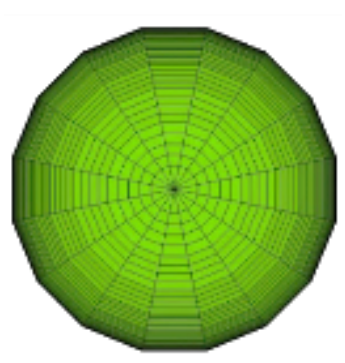

Vista superior

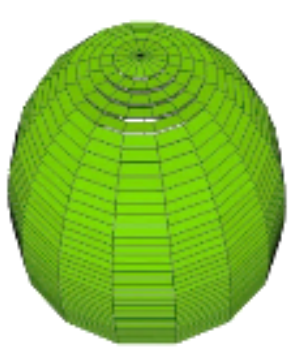

Perspectiva

Figura 9 - Modelo geométrico - método com material translúcido

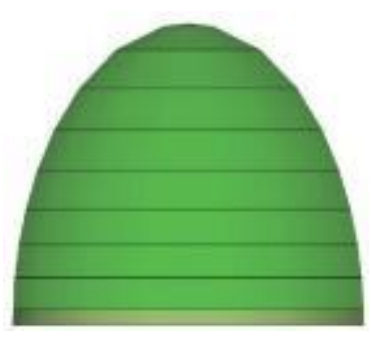

Vista frontal

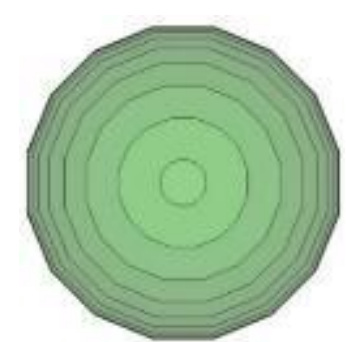

Vista superior

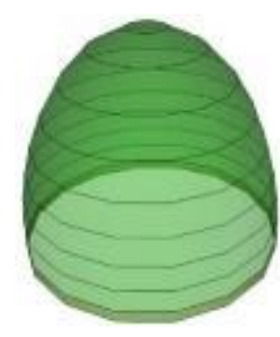

Perspectiva 
Figura 10 - Modelo geométrico - método com inserção de frestas

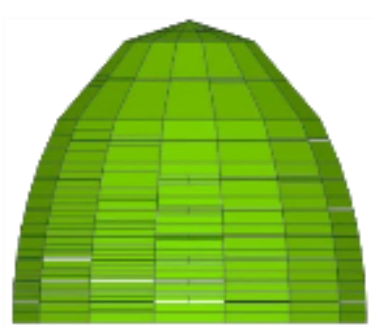

Vista frontal

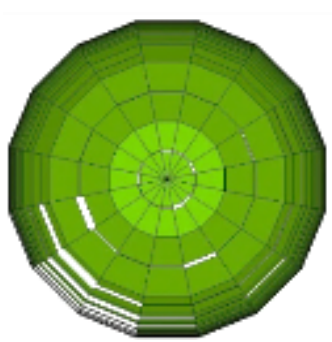

Vista superior

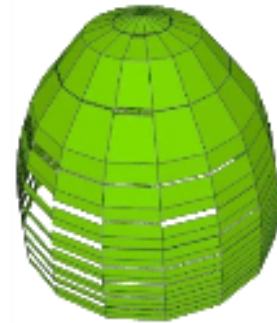

Perspectiva

Fonte: Lima (2014).

Figura 11 - Modelo geométrico de uma das árvores e do entorno delas

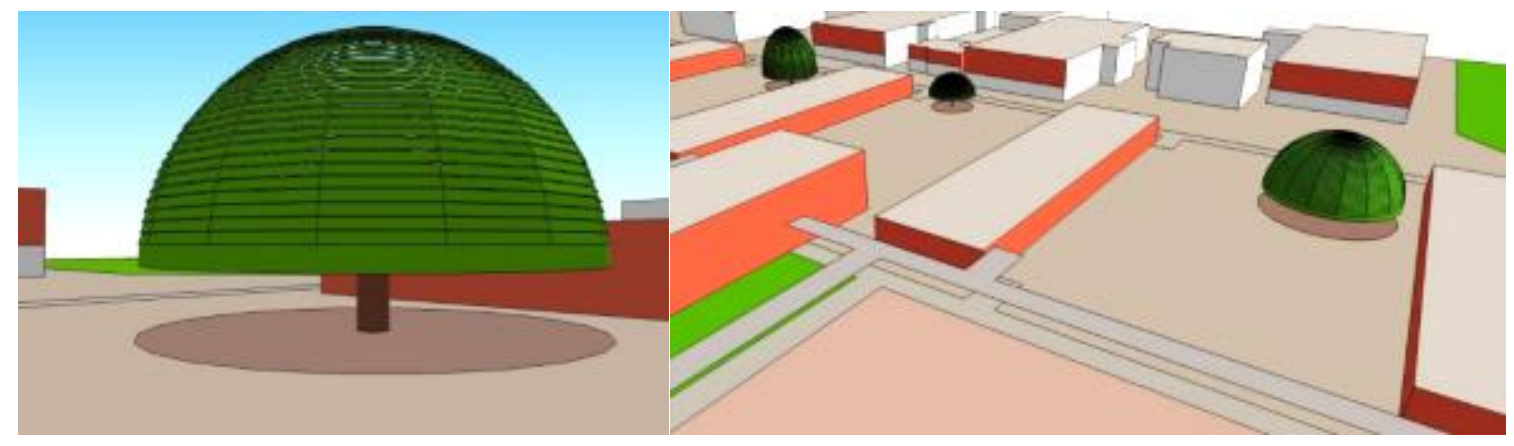

A ferramenta computacional Daysim 3.1 beta foi empregada nas simulações. O programa simula as condições de iluminação natural por um período anual (simulação dinâmica) e considera as condições reais de disponibilidade de luz natural com base no ano típico de referência (typical reference year - TRY) da cidade de João Pessoa, PB.

Para cada dia de medição (in loco) foi associado um dia correspondente na simulação. Para a seleção dos dias análogos analisou-se o arquivo climático TRY, verificando-se as médias aritméticas dos dados de iluminância horizontal global correspondente aos horários de $11 \mathrm{~h}$ até $13 \mathrm{~h}$ nos meses de junho a agosto (período das medições). Essas médias foram comparadas com as médias aritméticas da iluminância externa, verificada in loco, observando-se ainda a condição de céu descrita nas medições. Assim, para a utilização na análise dos dados da simulação foi possível selecionar os dias que apresentam condições de céu similares às medições in loco. Os dados de simulação da iluminância sob a copa de cada tipo arbóreo foram organizados em planilhas, dispostos por condição de céu, em função da orientação e do intervalo de tempo (11h até $13 \mathrm{~h})$ a cada $1 \mathrm{~min}$.

\section{Tratamento e análise estatística dos dados}

Como mencionado anteriormente, o desenvolvimento desta pesquisa realizou-se em duas etapas:

(a) levantamento de campo - medições da iluminância e aquisição das fotografias olho de peixe; e

(b) simulações computacionais.

Para validar os resultados e verificar em que medida os modelos geométricos virtuais representam adequadamente as árvores reais, foi realizada a análise comparativa entre os dados de iluminância medidos in loco sob a copa dos indivíduos estudados e a iluminância obtida com os modelos geométricos simulados. Os dados (iluminâncias medida e simulada) foram organizados em planilhas em função do tipo de céu e, em seguida, com o auxílio do software estatístico $\mathrm{R}$, analisados através de gráficos boxplot, que indicam os níveis de dispersão da amostra.

Através das diferenças entre os quartis $(50 \%$ da amostra), verificou-se a redução na variação da iluminância. Obteve-se ainda a variação relativa das medianas. Esses cálculos foram realizados para as duas condições de obstrução: sensor externo (no 
ponto mais elevado do entorno) e sensores sob a copa das árvores.

Para cada conjunto de dados foi aplicado o teste de normalidade Shapiro Wilk com nível de significância de 0,05 e intervalo de confiança de $95 \%$, a fim de verificar se as amostras seguem uma distribuição normal e, ainda, de definir se os testes a serem aplicados posteriormente devem ser paramétricos ou não paramétricos. Através do coeficiente de correlação de postos de Spearman (não paramétrico) foi verificada a correlação existente entre a amostra da iluminância medida in loco e a amostra da iluminância simulada para cada modelo.

Por último, realizou-se uma análise geral das diferenças encontradas entre medição e simulação, descrevendo os erros em relação às medições de referência. Para isso foram utilizados os seguintes indicativos estatísticos: erro médio quadrático relativo (RMSE rel - relative root mean square error) e o desvio das médias relativo (MBErel relative mean bias error), segundo método adotado por Reinhart e Walkenhorst (2001), definidos nas Equações 1 e 2, abaixo:

$$
\begin{aligned}
& M B E_{\text {rel }}=\frac{1}{N} \sum_{i=1}^{N}\left(\frac{\left(I L_{S}-I L_{M}\right)}{I L_{M}}\right) \\
& R M S E_{r e l}=\frac{1}{N} \sqrt{\sum_{i=1}^{N}\left(\frac{\left(I L_{S}-I L_{M}\right)^{2}}{I L_{M}^{2}}\right)}
\end{aligned}
$$

Onde:

IL $_{S}$ é a iluminância simulada; e

$\mathrm{IL}_{\mathrm{M}}$ é a iluminância medida.

De acordo com Reinhart e Walkenhorst (2001), esses indicativos caracterizam as semelhanças e/ou diferenças entre dois conjuntos de dados de iluminação natural, simulados e medidos. O $\mathrm{RMSE}_{\text {rel }}$ é a medida da magnitude média dos erros estimados, tem valor sempre positivo e, quanto mais próximo de zero, maior a qualidade da iluminância simulada. $\mathrm{O} \mathrm{MBE}_{\text {rel }}$ indica o quanto a iluminância simulada está sendo subestimada (valor negativo) ou superestimada (valor positivo) em relação à iluminância medida. $\mathrm{O}$ ideal é que o valor de $\mathrm{MBE}_{\text {rel }}$ tenda a zero.

Para validar os resultados produzidos através do $\mathrm{MBE}_{\text {rel }}$ e RMSErel, tomaram-se como referência estudos anteriores que utilizaram esses indicativos, tais como Villalba, Pattini e Correa (2014), AlSallal e Al-Rais (2013), Reinhart e Breton (2009) e Reinhart e Walkenhorst (2001).

\section{Resultados e discussões}

Os resultados da pesquisa são apresentados considerando três abordagens: as iluminâncias de referência; as imagens olho de peixe; e a comparação entre medições e simulações.

\section{Iluminâncias de referência}

Na Figura 12 é possível observar a dispersão dos dados de iluminância (klux) registrados no sensor externo (desobstruído), como também os pontos discrepantes (outliers). Na condição de céu claro $50 \%$ das ocorrências de iluminância estão entre 95 e 103 klux, o que corresponde a uma variação relativa de $8,4 \%$. Para os registros na condição de céu parcialmente encoberto observa-se maior variabilidade da luz, onde $50 \%$ das ocorrências se concentraram entre 48,8 e 100,8 klux, equivalente a $106,5 \%$ de variação relativa. Na condição de céu encoberto foram registradas as menores iluminâncias. Em 50\% da amostra as iluminâncias estão concentradas entre 33 e 63 klux $(90,9 \%$ de variação relativa).

Figura 12 - Distribuição da iluminância em entorno desobstruído para cada condição de céu

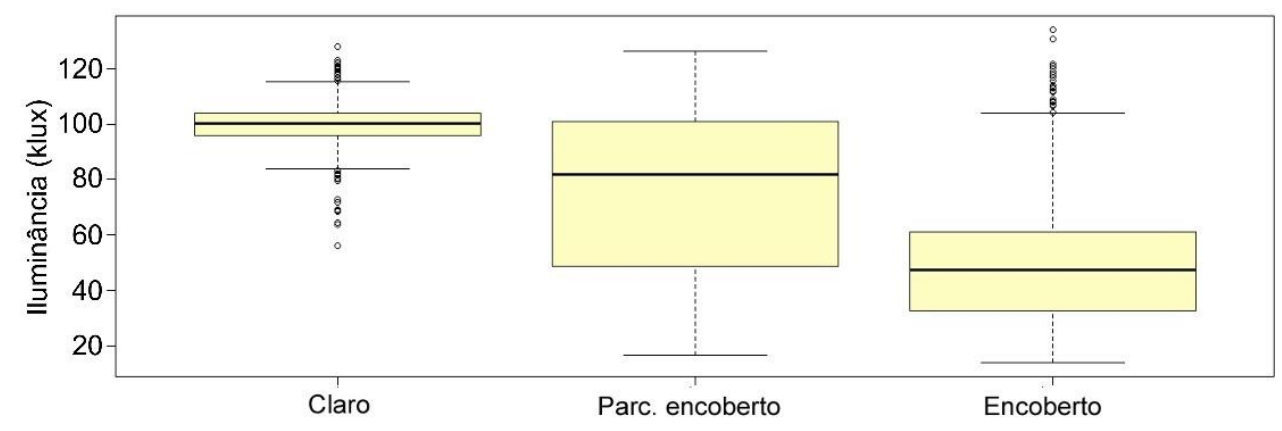


A menor variação e os níveis mais elevados de iluminância ocorreram nos dias de céu claro devido à homogeneidade desse tipo de céu, sem significativa presença de nuvens. Na condição de céu encoberto foram registrados os níveis de iluminância mais baixos, com variabilidade intermediária. Os menores registros de iluminâncias se devem ao fato de que em um céu completamente encoberto não há luz solar direta atingindo o solo e a coroa solar não é visível. Além disso, a porção zenital apresenta luminância maior que a porção próxima à linha do horizonte. Nos dias de céu parcialmente encoberto ocorreu maior variação da iluminância, decorrente da heterogeneidade do céu (presença de nuvens que não cobrem totalmente a abóbada celeste). Segundo Souza e Pereira (2004), esse tipo de céu é o mais frequente no território brasileiro, portanto deve ser considerado em estudos de iluminação natural.

As iluminâncias medidas sob a copa dos indivíduos estudados estão apresentadas nas Figuras 13, 14 e 15. Nestes, os dados espúrios (que neste estudo correspondem a 2\%) foram eliminados da amostra. Em todos os casos a mangueira e a carolina apresentaram menor amplitude da iluminância, o que pode ser associado à alta densidade e homogeneidade da copa dessas espécies (Figura 16), enquanto o paubrasil e a pitombeira tiveram maior amplitude e níveis de iluminação mais elevados. Especialmente na condição de céu claro e parcialmente encoberto a mangueira apresentou os menores níveis de iluminação. Tendo em conta a amplitude e os níveis de iluminância, o pau-brasil e a pitombeira assemelham-se. A mangueira e a carolina também apresentam comportamento similar, com a ressalva de que os níveis de iluminância são consideravelmente diferenciados.

\section{Processamento e análise das imagens olho de peixe}

Esta etapa trata das imagens olho de peixe, registradas sob a copa dos indivíduos em estudo. Com as imagens obtiveram-se dados de "fração de lacuna" a partir dos quais foi possível, juntamente com a geometria da copa, desenvolver o modelo geométrico virtual que melhor se ajusta às árvores estudadas. A Figura 16 demonstra, em intervalos percentuais, os valores de "fração de lacuna" das copas em estudo.

Figura 13 - Distribuição da iluminância sob condição de céu claro

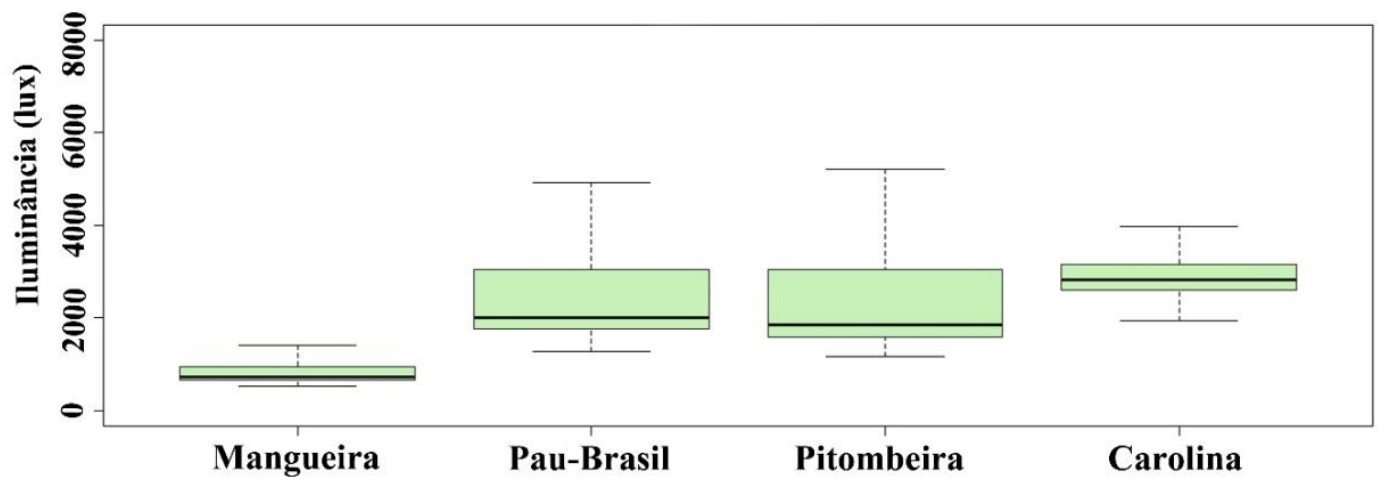

Figura 14 - Distribuição da iluminância sob condição de céu parcialmente encoberto

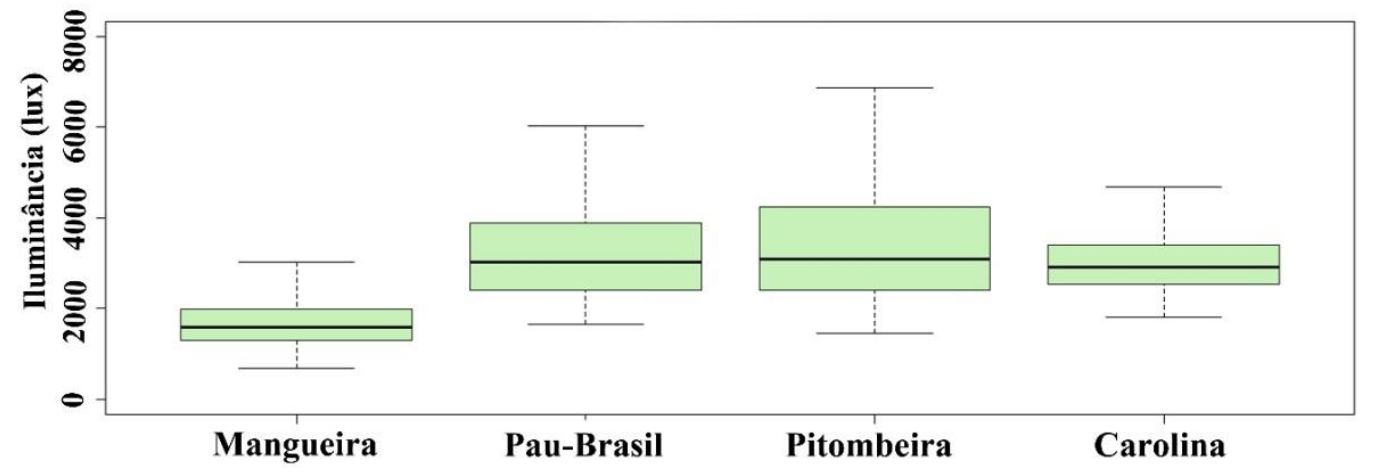

244 Lima, E. de F. C.; Leder, S. M. 
Figura 15 - Distribuição da iluminância sob condição de céu encoberto

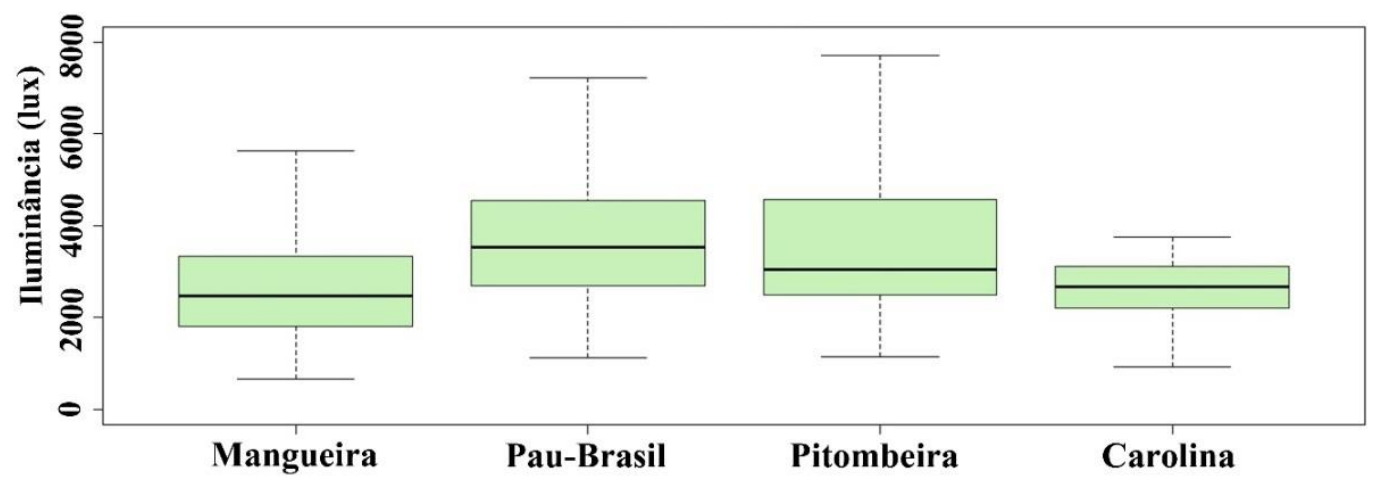

Figura 16 - Percentuais de lacuna da copa das espécies arbóreas em função do ângulo zenital

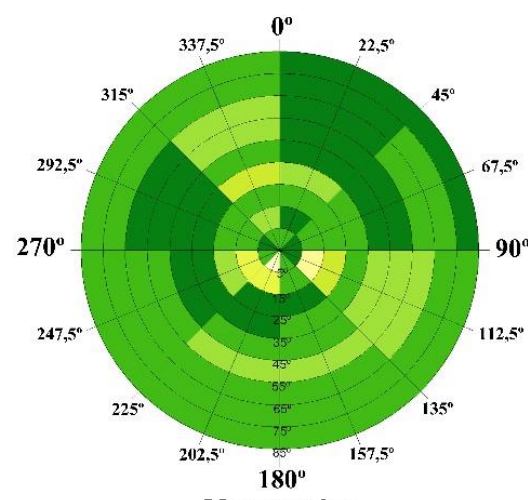

Mangueira

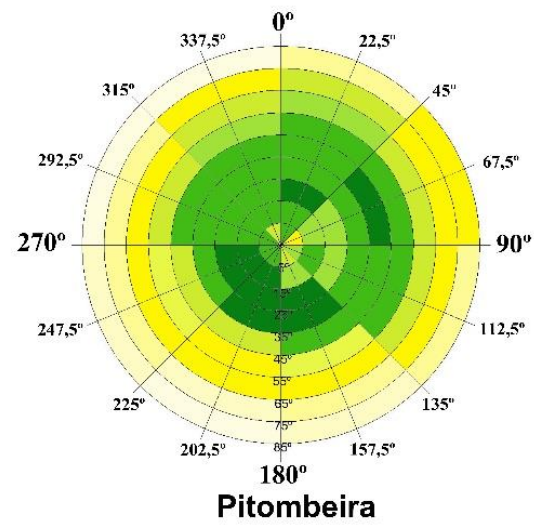

Fonte: Lima (2014).

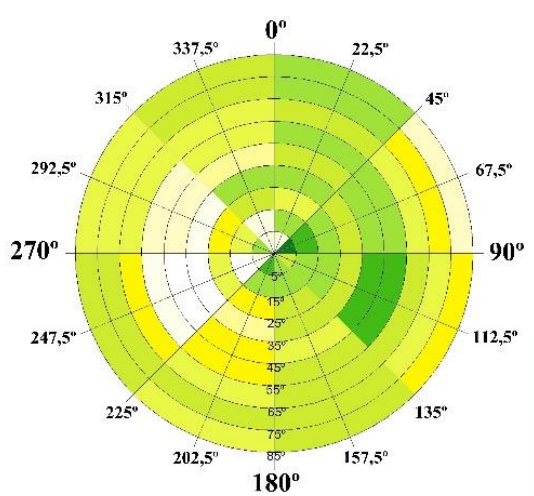

Pau-Brasil

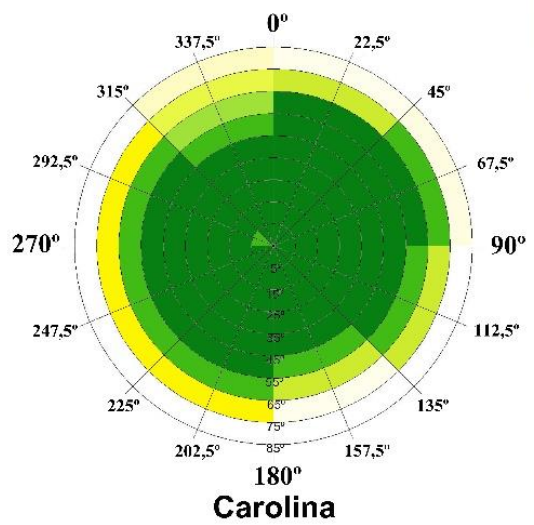

Percentual de Lacuna

$0-2 \%$

$2 \%-4 \%$

$4 \%-6 \%$

$6 \%-8 \%$

$8 \%-10 \%$

$10 \%-12 \%$

$12 \%-14 \%$

$14 \%-16 \%$

$16 \%-18 \%$

$18 \%-20 \%$

$>20 \%$
Observa-se que a mangueira apresenta percentual de lacunas com distribuição mais uniforme em função do ângulo zenital. A pitombeira apresentou os valores mais elevados, ficando entre $7,5 \%$ e $11,0 \%$, que corresponde à copa mais permeável à passagem da luz. A espécie mangueira apresentou valores relativamente baixos, entre $2,0 \%$ e $5,2 \%$, indicando que se trata de uma árvore de copa fechada e densa. A espécie carolina caracteriza-se como uma copa com alto grau de densidade em seu centro, diminuindo gradativamente até sua base. $\mathrm{O}$ menor percentual de lacuna $(0,3 \%)$ ocorreu no ângulo zenital de $15^{\circ}$, e a maior ocorrência foi de $21 \%$ no ângulo de $85^{\circ}$. O paubrasil apresentou níveis de "fração de lacuna" mais elevados, que aumentam gradativamente a partir de $45^{\circ}$ até $85^{\circ}$, base da copa. O menor percentual atingido foi de $2,5 \%$, chegando a $15,0 \%$.

Para cada árvore foi calculada a média aritmética dos dados de abertura de copa, correspondentes a cada orientação, conforme a Figura 17. Observa-se que a mangueira é a árvore que apresentou copa mais fechada, seguida da carolina. A pitombeira e o pau-brasil apresentaram os maiores percentuais 
de abertura, tendo a copa do pau-brasil as maiores lacunas, aproximadamente $9 \%$ do todo.

Traçando-se uma relação entre o percentual de abertura da copa em cada fotografia olho de peixe e as medianas das medições da iluminância sob a copa, correspondentes a cada orientação, obteve-se a Figura 18. A partir da linha de tendência observa-se que a quantidade de iluminação que incide sob a copa guarda estreita relação com a variável "fração de lacuna" ou o percentual de abertura de copa. Assim, pode-se afirmar que essa variável tem influência significativa no desempenho da iluminância.

\section{Análise comparativa entre iluminância medida e simulada}

Nesta secção os conjuntos de dados de medição in loco e simulação, correspondentes ao sensor externo, foram agrupados em função do tipo de céu. Assim, as variáveis "orientação" e "horário" não foram consideradas. Observa-se, segundo a Figura 19, que a condição de céu encoberto apresenta maior paridade na dispersão dos dados de iluminância medida in loco e simulada.

Figura 17 - Percentual de abertura de copa por espécie arbórea

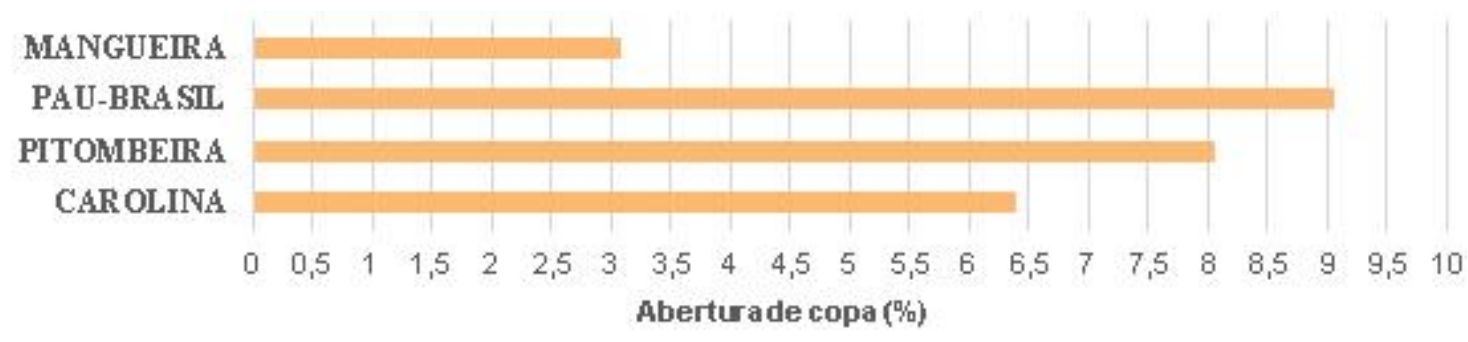

Fonte: Lima (2014).

Figura 18 - Relação entre abertura de copa e iluminância sob a copa das espécies arbóreas estudadas

MANGUEIRA

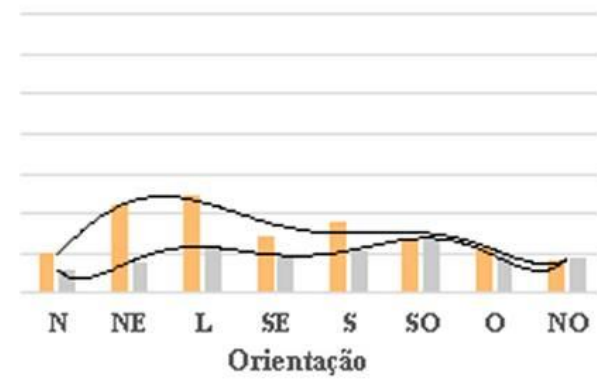

PITOMBEIRA

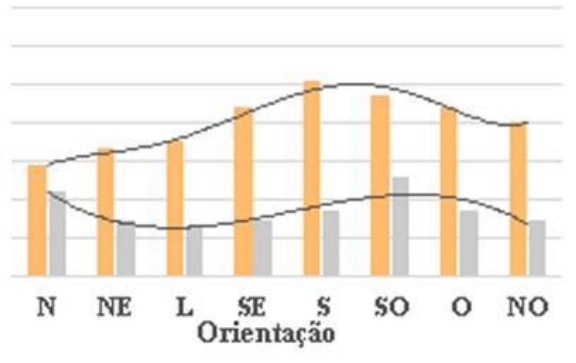

Abertura de copa (\%)
PAU-BRASIL

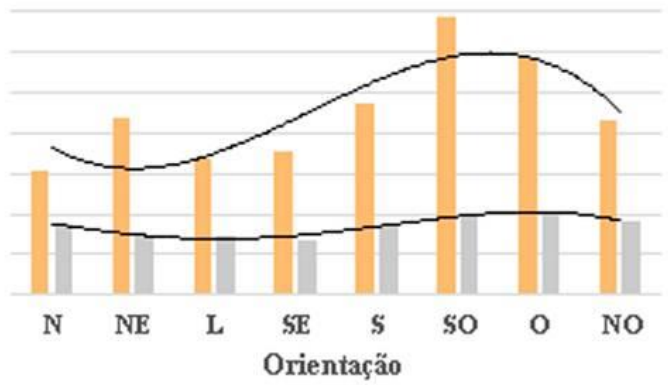

CAROLINA

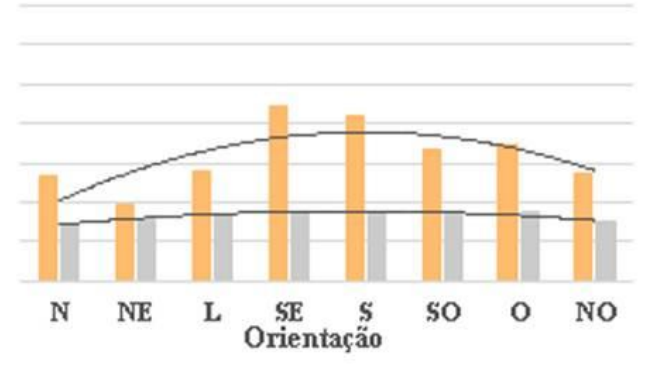

Iluminância sob a copa (\%)

Fonte: Lima (2014). 
Figura 19 - Níveis de dispersão para as medições in loco e simulações para entorno desobstruído

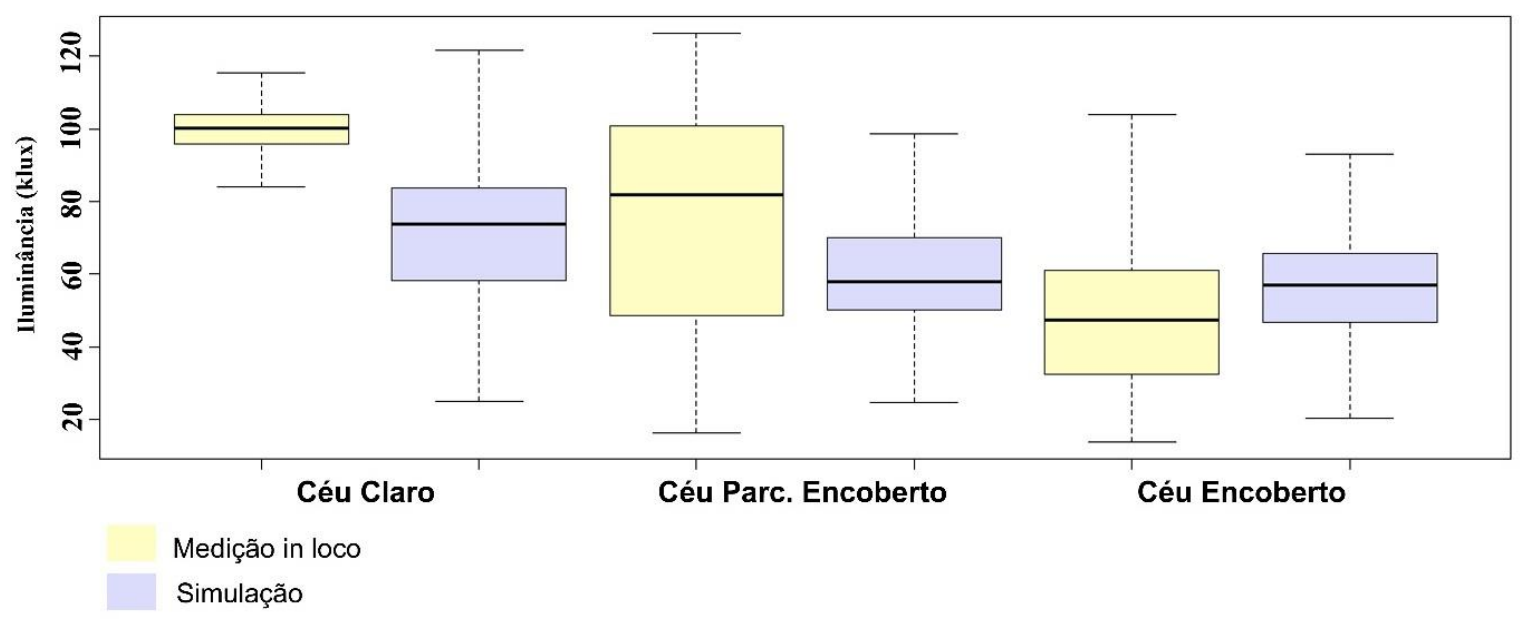

Para a condição de céu claro e parcialmente encoberto há diferença significativa entre as medianas da medição e simulação, aproximadamente 27 klux (céu claro) e 24 klux (parcialmente encoberto). Na condição de céu encoberto a diferença apresentada entre as medianas é de cerca de 10 klux. Quanto à variação relativa, levando em conta a diferença entre quartis (50\% da amostra), observa-se na Tabela 1 que o conjunto de dados correspondentes ao céu encoberto apresenta maior semelhança quanto à variabilidade. Através do coeficiente de correlação de postos de Spearman verificou-se a correlação existente entre a amostra da iluminância medida e a amostra da iluminância simulada em cada condição de céu (Tabela 1). Em todos os casos constataram-se correlações fracas, e na condição de céu encoberto ocorreu o valor mais elevado.

Assim, considerando que o céu encoberto apresentou maior semelhança nos níveis e na dispersão entre os conjuntos de dados optou-se pela utilização dos dados de céu encoberto para as comparações subsequentes.

A análise comparativa para cada modelo geométrico virtual está descrita nos itens que seguem. É conveniente destacar que os conjuntos de dados de medição in loco sob a copa das árvores apresentam picos de iluminância em certos horários que os tornam bastante discrepantes em relação à maioria dos valores. Assim, optou-se por eliminar os dados espúrios das amostras, correspondentes a $20 \%$, a fim de obter melhor ajuste entre os dados medidos e os simulados. Dessa forma, a análise comparativa foi realizada com $80 \%$ da amostra total de cada conjunto de dados. A exclusão dos dados considerados espúrios justifica-se pelo entendimento de que os valores excessivos (portanto, discrepantes do conjunto) resultam de momentos em que houve incidência da luz do sol sobre o sensor, causada pela distribuição não homogênea das folhas da copa (vazios) e pelo movimento delas com o vento.

A comparação do comportamento dos três modelos geométricos que representam as espécies arbóreas está apresentada na Figura 20. Para o modelo 1 (composto de superfícies inclinadas - persianas) observa-se que o modelo que representa o paubrasil possui maior aproximação com a árvore real, apresentando, para $50 \%$ da amostra (diferença entre quartis), variação absoluta de 756 lux, ao passo que as medições in loco demonstram variação de 1.846 lux, resultando em redução da variação da iluminância de 59,05\%. Observando as medianas medidas e as simuladas (Tabela 2), as maiores aproximações, considerando o pau-brasil, ocorreram também para o modelo 1, com diferença de 625 lux, que corresponde à variação relativa de $23,97 \%$.

Tomando como base os dados do sensor externo e considerando o modelo 1 , os percentuais de redução na variação da iluminância simulada em relação à iluminância medida e a variação relativa das medianas são mostrados no Gráfico 10. Notase que dos tipos arbóreos o pau-brasil e a mangueira apresentam maior semelhança com as medições.

De acordo com a Figura 21, o comportamento do modelo 2, composto de superfície translúcida, apresenta maior aproximação, considerando a mediana, com o exemplar da mangueira. No entanto, quanto à variação da iluminância para $50 \%$ da amostra, a maior similaridade ocorre para o pau-brasil. Como pode ser observado na Tabela 2 , as medianas obtidas com o modelo digital da mangueira e com a árvore real têm diferença aproximada de 437 lux, correspondendo à variação relativa de $23,6 \%$. A variação absoluta do modelo 
que representa a mangueira corresponde a 378 lux, sendo a redução na variação da iluminância em relação à árvore real de 66,99\%. Ainda considerando o modelo 2 , o modelo que representa a mangueira também é o que possui comportamento semelhante à iluminância externa, quanto aos percentuais de redução da variação da iluminância simulada em relação à iluminância medida e à variação relativa das medianas.

Tomando como referência o percentual de redução da variação da iluminância e a variação relativa das medianas do sensor em entorno desobstruído, entre as espécies arbóreas a que possui maior semelhança ao que ocorre no ambiente externo é o pau-brasil, seguida da mangueira (Figura 21).

O modelo 3 (frestas), entre os demais, é o que mais se assemelha, considerando os níveis de dispersão, ao comportamento das quatro espécies arbóreas escolhidas. A pitombeira apresentou a maior aproximação em relação à variação relativa das medianas, com 1,09\% de diferença (33 lux de variação absoluta). $\mathrm{O}$ maior ajuste em termos de variação absoluta de $50 \%$ da amostra ocorreu para o pau-brasil, com redução na variação da iluminância em relação à árvore real de apenas $19,10 \%$.

Para cada indivíduo estudado, verificou-se a correlação existente entre a amostra da iluminância medida e a iluminância simulada. Obteve-se o nível de relacionamento entre os conjuntos de dados através do coeficiente de correlação de postos de Spearman (não paramétrico). De acordo com a Tabela 3, ao observar o nível de associação entre a iluminância medida in loco e a simulada, nota-se que em todos os casos as correlações são consideradas fracas. No entanto, podemos afirmar que a mangueira, a pitombeira e a carolina são mais bem representadas pelo modelo 1 (persianas), e o pau-brasil pelo modelo 3 (frestas).

Tabela 1 - Variação absoluta e correlação entre medições e simulações

\begin{tabular}{c|c|c|c|c|c|c}
\hline & \multicolumn{2}{|c|}{ Céu claro } & \multicolumn{2}{c|}{ Céu parc. encoberto } & \multicolumn{2}{c}{ Céu encoberto } \\
\hline & Medição & Simulação & Medição & Simulação & Medição & Simulação \\
\hline $\begin{array}{c}\text { Variação } \\
\text { absoluta }\end{array}$ & 7.922 lux & 25.540 lux & 51.970 lux & 19.672 lux & 28.432 lux & 18.924 lux \\
\hline $\begin{array}{c}\text { Coeficiente } \\
\text { de correlação }\end{array}$ & \multicolumn{2}{|c|}{$-0,191$} & \multicolumn{2}{c|}{$-0,013$} & \multicolumn{2}{c}{0,322} \\
\hline
\end{tabular}

Figura 20 - Níveis de dispersão dos tipos arbóreos para os dados medidos in loco e simulados
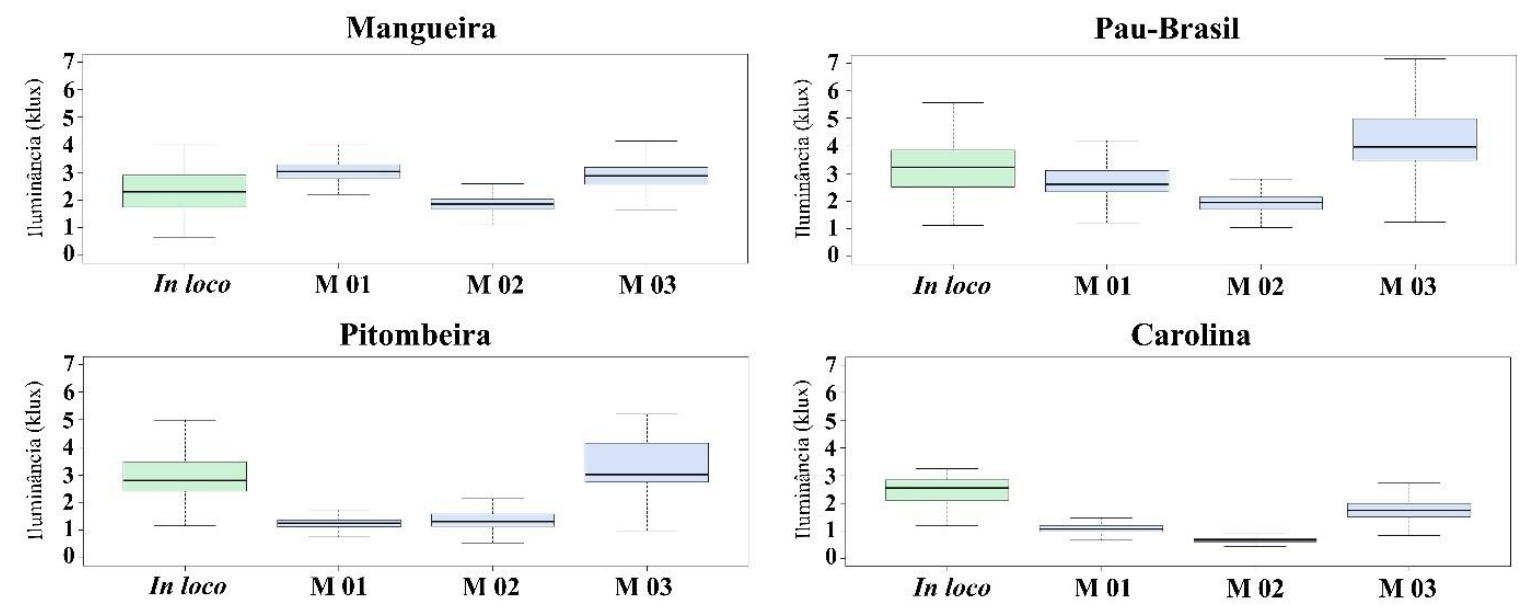

Fonte: Lima (2014).

Tabela 2 - Medianas e variação absoluta de 50\% da amostra para medições e modelos simulados

\begin{tabular}{|c|c|c|c|c|c|c|c|c|}
\hline & \multicolumn{2}{|c|}{ Medição in loco } & \multicolumn{2}{|c|}{ Modelo 1} & \multicolumn{2}{|c|}{ Modelo 2} & \multicolumn{2}{|c|}{ Modelo 3} \\
\hline & Mediana & Variação & Mediana & Variação & Mediana & Variação & Mediana & Variação \\
\hline Mangueira & $2.291 \operatorname{lux}$ & $1.145 \operatorname{lux}$ & $3.044 \operatorname{lux}$ & $510 \operatorname{lux}$ & $1.854 \operatorname{lux}$ & $378 \operatorname{lux}$ & $2.886 \operatorname{lux}$ & $630 \operatorname{lux}$ \\
\hline Pau & 3.23 & $1.846 \mathrm{ll}$ & 2.607 & 7561 & 1.956 & 449 lux & 3.966 lux & $1.494 \operatorname{lux}$ \\
\hline Pitom & $3.049 \operatorname{lux}$ & $2.085 \operatorname{lux}$ & $1.250 \operatorname{lux}$ & $251 \operatorname{lux}$ & 1.307 lux & $388 \operatorname{lux}$ & 3.016 lux & 1.411 lux \\
\hline Carolina & 2.672 lux & 907 lux & 649 lux & 125 lux & $649 \operatorname{lux}$ & $125 \operatorname{lux}$ & 1.742 lux & $488 \operatorname{lux}$ \\
\hline
\end{tabular}

248 Lima, E. de F. C.; Leder, S. M. 
Figura 21 - Redução na variação da iluminância e variação relativa das medianas

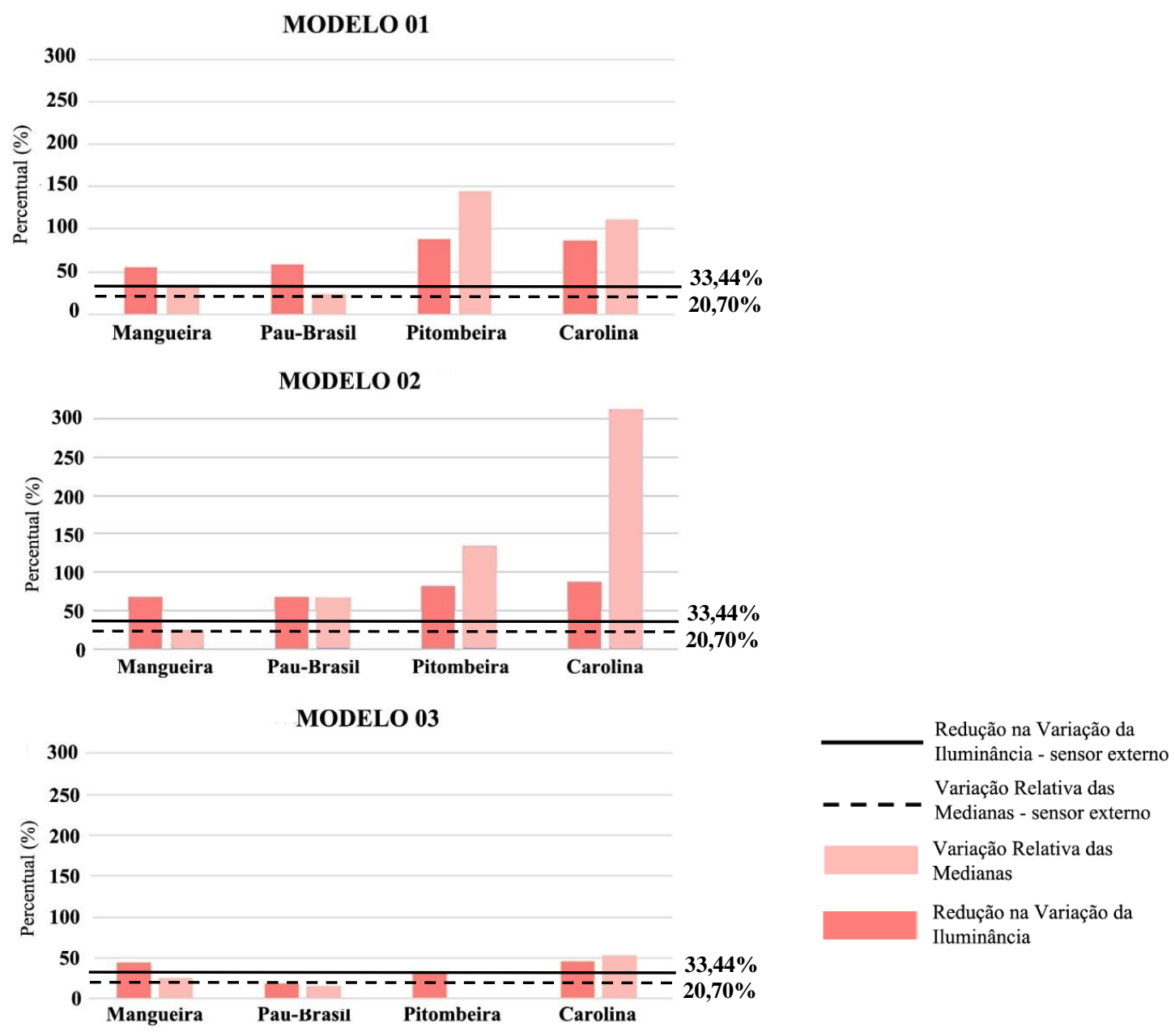

Tabela 3 - Resultado do teste de correlação de Spearman

\begin{tabular}{l|c|c|c|c}
\hline \multicolumn{5}{c}{ Correlação de postos de Spearman } \\
\hline & Mangueira & Pau-brasil & Pitombeira & Carolina \\
\hline Modelo 1 & 0,15 & 0,09 & $-0,30$ & 0,12 \\
Modelo 2 & 0,09 & 0,05 & $-0,03$ & 0,01 \\
Modelo 3 & 0,10 & 0,13 & 0,05 & $-0,09$ \\
\hline
\end{tabular}

\section{Análise de erros}

Foi realizada uma análise das diferenças encontradas entre medição e simulação, descrevendo os erros em relação às medições de referência. Para isso foram utilizados os indicativos estatísticos RMSErel e MBErel.

Como se sabe, o ideal é que os valores de MBErel e RMSErel tendam a zero, garantindo, assim, maior confiabilidade da iluminância simulada. Estudos similares de simulação dinâmica da iluminação natural utilizam como critério o limite de $25 \%$ de erro relativo, comparando simulações com medições (MARDALJEVIC, 2000; REINHART; WALKENHORST, 2001; REIHART;
ANDERSEN, 2006; REINHART; BRETON, 2009; REINHART, 2011). Al-Sallal e Al-Rais (2013) consideram que a margem de erro para MBEs e RMSEs em modelagens de árvores não deve ser superior a 20\%, com um nível de confiança estatística de $80 \%$.

Os valores destacados em vermelho na Tabela 4 ultrapassam a margem de erro de $25 \%$. De acordo com esse critério, o modelo 2 (translúcido) adequou-se apenas à mangueira e apresentou MBErel de -0,099 e RMSErel de 0,013. Esses valores, além de estarem abaixo do critério adotado como limite, são também os menores valores do grupo. O modelo 1 (persianas) também se adequou apenas a uma espécie, a mangueira, 
com MBE de -0,075 e RMSErel de 0,013. O modelo 3 (frestas) apresentou resultados satisfatórios para duas espécies: a pitombeira, MBErel de 0,211 e RMSErel de 0,02, e a carolina, com MBErel de $-0,129$ e RMSErel de 0,030, configurando-se como o modelo de melhor performance.

\section{Considerações finais}

Nesta pesquisa buscou-se aprimorar um método de medição da permeabilidade da vegetação arbórea à passagem da luz natural e sua aplicação no desenvolvimento de modelos digitais para utilização em simulação computacional. As principais características de permeabilidade da luz natural em quatro espécies arbóreas (mangueira, pau-brasil, pitombeira e carolina) foram medidas in loco, em indivíduos reais. As medidas obtidas, especialmente a "fração de lacuna da copa", foram empregadas na construção de modelos virtuais simplificados. Por fim, os resultados das medições de iluminância in loco foram comparados com simulações computacionais da iluminação natural, visando averiguar a eficácia dos modelos propostos.

Na comparação dos dados medidos e simulados observou-se que os níveis de dispersão dos grupos de dados (medição e simulação) demonstram que, entre os modelos estudados, o modelo 3 (frestas) é o que melhor representa o comportamento real das quatro espécies arbóreas escolhidas. Considerando a dispersão e a mediana, melhores ajustes ocorreram para o modelo 1 (persianas) com o paubrasil, para o modelo 2 (translúcido) com a mangueira e para o modelo 3 (frestas) com a pitombeira e a carolina.
O coeficiente de correlação de Spearman para os modelos simulados e as árvores reais resultou em correlações fracas, porém significativas, tendo os maiores valores ocorrido na simulação com os modelos 1 (persianas) e 3 (frestas).

Por fim, a análise de erro das diferenças encontradas entre medição e simulação foi realizada através dos indicadores estatísticos MBErel e RMSErel. Os modelos 1 (persianas) e 2 (translúcido) apresentaram erros aceitáveis para uma espécie apenas, respectivamente o pau-brasil e a mangueira. $\mathrm{O}$ modelo 3 , por apresentar erros dentro dos limites aceitáveis para duas espécies arbóreas, foi considerado de melhor desempenho: a pitombeira, com MBErel de 0,211 e RMSErel de 0,02 , e a carolina, com MBErel de $-0,129$ e RMSErel de 0,030.

Os valores obtidos nesta pesquisa com os indicativos MBErel e RMSErel são coerentes com os resultados de estudos anteriores e atendem aos critérios considerados satisfatórios. Diferenças entre resultados de medições e simulações são normais na prática da simulação devido às simplificações dos fenômenos luminosos ocorridos, especialmente no caso de simulações computacionais envolvendo elementos tão complexos como copas de árvores.

Assim, conclui-se que os modelos digitais simplificados de árvores testados neste trabalho, especialmente o modelo de frestas, são adequados à simulação da permeabilidade da copa à passagem da luz natural. Contudo, os modelos digitais simplificados dependem do "fator de lacuna" da espécie arbórea que se deseja simular, obtido através de medida in loco, que é, ainda, um processo complexo, cuja simplificação deverá ser objeto de pesquisas subsequentes.

Tabela 4 - Erro médio quadrático - RMSErel e o desvio das médias - MBErel

\begin{tabular}{c|l|c|c|c|c}
\hline Modelo & & Mangueira & Pau-brasil & Pitombeira & Carolina \\
\hline \multirow{2}{*}{01} & MBErel & $\mathbf{0 , 4 0 5}$ & $\mathbf{- 0 , 0 7 5}$ & $\mathbf{- 0 , 5 4 1}$ & $\mathbf{- 0 , 4 7 8}$ \\
& RMSErel & $\mathbf{0 , 0 2 5}$ & $\mathbf{0 , 0 1 3}$ & $\mathbf{0 , 0 2 1}$ & $\mathbf{0 , 0 , 6}$ \\
\hline \multirow{2}{*}{02} & MBErel & $\mathbf{- 0 , 0 9 9}$ & $\mathbf{- 0 , 3 4 7}$ & $\mathbf{- 0 , 5 0 2}$ & $\mathbf{- 0 , 6 7 4}$ \\
& RMSErel & $\mathbf{0 , 0 1 3}$ & $\mathbf{0 , 0 1 5}$ & $\mathbf{0 , 0 , 9}$ & $\mathbf{0 , 0 2 7}$ \\
\hline \multirow{2}{*}{$\mathbf{0 3}$} & MBErel & $\mathbf{0 , 3 4 6}$ & $\mathbf{0 , 3 3 9}$ & $\mathbf{0 , 2 1 1}$ & $\mathbf{- 0 , 1 2 9}$ \\
& RMSErel & $\mathbf{0 , 0 2 4}$ & $\mathbf{0 , 0 2 2}$ & $\mathbf{0 , 0 2 0}$ & $\mathbf{0 , 0 3 0}$ \\
\hline
\end{tabular}

Nota: *valores destacados em vermelho ultrapassam a margem de erro de $25 \%$. 


\section{Referências}

AL-SALLAL, K. A.; AL-RAIS, L. A Novel Method to Model Trees for Building Daylighting Simulation Using Hemispherical Photography. Journal of Building Performance Simulation, v. 6, n. 1, p. 38-52, jan. 2013.

BERRY, R.; LIVESLEY, S. J.; AYE, L. Tree Canopy Shade Impacts on Solar Irradiance Received by Building Walls and Their Surface Temperature. Building and Environment, v. 69, p. 91-100, 2013.

BARTHOLOMEI, C. L. B. Influência da Vegetação no Conforto Térmico Urbano e no Ambiente Construído. Campinas, 2003. 144 f. Tese (Doutorado em Engenharia Civil) - Escola de Engenharia, Universidade Estadual de Campinas, Campinas, 2003.

CHARTERED INSTITUTION OF BUILDING SERVICES. Lighting Guide 11 RSC: Surface Reflectance Sample Card. London, 2001.

DURANTE, L.; NOGUEIRA, M. C. J. A. Efeitos do Sombreamento Arbóreo nas Condições Termohigrométricas e Lumínicas de Ambientes Internos e Externos de Edificações. Gestão, Educação e Tecnologia Ambiental, v. 9, n. 9, p. 1980-1998, fev. 2013.

FRAZER, G. W.; CANHAM, C. D.; LERTZMAN, K. P. Gap Light Analyzer (GLA), Version 2.0: imaging software to extract canopy structure and gap light transmission indices from true-colour fisheye photographs, user's manual and program documentation. Simon Fraser University, Burnaby, British Columbia, and the Institute of Ecosystem Studies, Millbrook, New York, 1999.

GOOGLE MAPS. [João Pessoa]. 2014. Disponível em:

<www.google.com.br/maps/place/João+Pessoa〉. Acesso em: 15 dez. 2014.

HOPKINSON, R.; LONGMORE, J.; PETHERBRIDGE, P. Iluminação Natural. Lisboa: Calouste Gulbenkian, 1975.

LIMA, E. F. C. Elementos Vegetais na Simulação Digital da Luz Natural: contribuição ao desenvolvimento de modelos tridimensionais virtuais. João Pessoa, 2014. 195 f. Dissertação (Mestrado em Engenharia Civil) - Escola de Engenharia, Universidade Federal da Paraíba, João Pessoa, 2014.

MARDALJEVIC, J. Simulation of Annual Daylighting Profiles for Internal Illuminance. Lighting Research and Technology, v. 32, p. 111-118, 2000.
MASCARÓ, L.; MOORE, J. L. Vegetação

Urbana. Porto Alegre: Masquatro, 2010.

PIVETA, J. Influência de Elementos Paisagísticos no Desempenho Térmico de Edificação Térrea. Londrina, 2010. 69 f. Dissertação (Mestrado em Engenharia Civil) Universidade Estadual de Londrina, Londrina, 2010.

REINHART, C. F.; WALKENHORST, O. Validation of Dynamic Radiance-Based Daylight Simulations for a Full-Scale Test Office With External Blinds. Energy and Buildings, v. 33, p. 683-697, 2001

REINHART, C. F.; ANDERSEN, M.

Development and Validation of a Radiance Model for a Translucent Panel. Energy and Buildings, v. 38, p. 890-904, 2006.

REINHART, C.; BRETON, P. F. Experimental Validation of Autodesk 3Ds Max1 Design 2009 and Daysim 3.0. Building Simulation, v. 6, p. 1514-1521, 2009.

REINHART, C. Daylight Performance Predictions. In: HENSEN, J.; LAMBERTS, R. (Eds.). Building Performance Simulation for Design and Operation. New York: Spon Press, 2011. v. 1, p. 235-276.

SCHNEIDER, D.; SCHWALBE, E.; MAAS, H. $\mathrm{G}$. Validation of geometric models for fisheye lenses. Journal of Photogrammetry and Remote Sensing, v. 64, p. 259-266, 2009.

SOUZA, R. V. G.; PEREIRA, F. O. R. Primeira Estação de Medição de Iluminação Natural em Território Brasileiro: análise dos dados dos dois primeiros anos de funcionamento. Ambiente Construído, Porto Alegre, v. 4, n. 3, p. 79-94, jul./set. 2004.

VILlALBA, A.; PATTINI, A.; CORREA, E. An Approach to Urban Tree Daylight Permeability Simulation Using Models Based on Louvers. Building and Environment, v. 73, p. 75-87, 2014.

YU, C.; HIEN, W. N. Thermal Benefits of City Parks. Energy and Buildings, v. 38, p. 105-120, 2006.

ZHANG, Y.; CHEN, J. M.; MILLER, J. R. Determining Digital Hemispherical Photograph Exposure for Leaf Area Index Estimation.

Agricultural and Forest Meteorology, v. 133, p. 166-181, 2005

ZHAO, D. et al. Can the Plant Area Index of a Submerged Vegetation Canopy Beestimated Using Digital Hemispherical Photography? Agricultural and Forest Meteorology, v. 192/193, p. 69-77, 2014. 


\section{Agradecimentos}

Os autores agradecem ao CNPq, pela bolsa de estudo concedida, que possibilitou esta pesquisa.
Agradecimentos especiais ao professor Luiz Bueno da Silva e ao pesquisador Erivaldo Lopes, do Laboratório de Análise do Trabalho - CT/UFPB, pelo auxílio na análise estatística.

Eliana de Fátima Costa Lima

Instituto Federal da Paraíba | Rua Projetada, s/n, Mocó | Itaporanga - PB - Brasil | CEP 58780-000 | Tel.: (83) 99176-7425 |

E-mail: ieliana_fcl@msn.com

\section{Solange Maria Leder}

Departamento de Arquitetura, Centro de Tecnologia | Universidade Federal da Paraíba | Campus I, Cidade Universitária, Castelo Branco | João Pessoa - PB - Brasil | CEP 58059-900 | Tel.: (83) 3216-7378 | E-mail: solangeleder@yahoo.com.br

\section{Revista Ambiente Construído}

Associação Nacional de Tecnologia do Ambiente Construído

Av. Osvaldo Aranha, $99-3^{\circ}$ andar, Centro

Porto Alegre - RS - Brasil

$$
\text { CEP } 90035-190
$$

Telefone: +55 (51) 3308-4084

Fax: +55 (51) 3308-4054

www.seer.ufrgs.br/ambienteconstruido

E-mail: ambienteconstruido@ufrgs.br 